\title{
Prime Borrowers and Financial Innovation in the Housing Boom and Bust*
}

\author{
Claes Bäckman ${ }^{\dagger}$ and Chandler Lutz ${ }^{\dagger}$
}

September 18, 2016

\begin{abstract}
We use the introduction of interest-only mortgages in Denmark as a natural experiment to assess the impact of alternative mortgage products on house prices during the 2000s. We construct a model to show that lower amortization payments lead to an increase in credit demand by allowing for better consumption smoothing, even absent any shift in credit supply. In support of the model, we find that the introduction of interest-only mortgages was followed by a large increase in the number of buyers, even as credit quality remained constant. On the aggregate level the results indicate that interest-only mortgages amplified the boom-bust pattern in housing: house prices increased an additional 35 percent during the boom, and subsequently reverse during the bust. These effects, which cannot be explained by changes in lending standards or shifts in credit supply, are magnified in local housing markets with higher ex-ante house price expectations. Together, the findings document the consequences of introducing IO loans on the micro- and macro level, and illustrates how new mortgage products can have large impacts even in the absence of a shift in credit supply.
\end{abstract}

JEL Classification: G01, R21, R31, E30, G21 R30

Keywords: Interest Only Mortgages, Housing Boom and Bust; Housing Affordability; Mortgage Lending; Synthetic Control

*This paper was previously circulated as "The Consequences of Interest-Only Loans for the Housing Boom and Bust". We would like to thank Amir Sufi, Danny Ben-Shahar, Fane Groes, Jens Lunde, João Cocco, Michael Møller, Ralf Wilkes and Søren Leth-Petersen, and seminar participants at Copenhagen Business School, the Conference on Housing Affordability, Denmark's Nationalbank, the Annual Conference for the International Association for Applied Econometrics, and the Riksbank for their helpful comments.

${ }^{\dagger}$ Copenhagen Business School, Department of Economics. Porcelœnshaven 16a, 2000 Frederiksberg, Denmark. Email: Bäckman cb.eco@cbs.dk; Lutz cl.eco@cbs.dk. Telephone: +45 38152575 


\section{Introduction}

The 2000s housing boom in the United States coincided with the permeation of alternative mortgage products that imploded into the worst economic downturn since the Great Depression. Many of these products aimed at improving affordability for households through reduced amortization payments, a valuable feature for households that wish to align their life-cycle consumption to their long-term income expectations (Cocco, 2013). During the same period, credit supply expanded rapidly following advances in securitization and increased sub-prime lending (Mian \& Sufi, 2009). Explanations for the housing boom in the United States have focused mainly on credit supply, and have put limited attention on the role of alternative mortgage products in the housing boom. In this paper, we use the introduction of a specific form of alternative mortgage products, interest-only (IO) loans, to answer two key questions: (1) how are households affected by the introduction of new mortgage products; and (2) what is the aggregate effect on house prices?

Interest-only mortgages were legalized through a rapidly implemented law change in Denmark in 2003, a highly regulated and conservative mortgage market. The political aim was to improve flexibility in mortgage financing for temporarily cash-constrained households. But as we will show, interest-only loans are valuable to a large fraction of the population, as amortization payments can be non-trivial. Indeed, for the average buyer in Copenhagen at the time of the legalization amortization payments were as high as 11 percent of annual disposable income. As Figure 1 shows, the legalization of IO loans led to a large increase in the number of housing transactions and an upwards spike in house prices. In the course of the housing boom that followed between 2004 and 2007, aggregate house prices increased by 62 percent. In comparison, the US S\&P/Case-Shiller 20-City Composite Home Price Index increased by 37 percent over the same time period.

To begin, we construct a three-period model with wealthy hand-to-mouth households (Kaplan et al. , 2014). The model formalizes the intuition in Cocco (2013), who 
shows empirically that households with high expected income growth are more likely to choose an alternative mortgage product. In the model, a reduction in amortization payments raise the attractiveness of investing in an illiquid asset (housing), because the increase in liquidity can be used to smooth consumption across periods. As the purchase of the illiquid asset is financed through debt, the model clearly shows that reducing amortizations causes an increase in credit demand, even absent any fundamental shifts in income. ${ }^{1}$ To test the model, we estimate the probability of buying a property for the full population of Danish households. We find that the fraction of households who purchase housing following the reform increase, even after controlling for a wide range of household- and municipality level variables, and that households with higher income growth had a larger increase in the probability of buying. Additionally, we use IO loan data from 2012 to show that IO loans were more prominent in areas with higher pre-treatment house price growth, and in municipalities with higher average income growth. These municipalities also experienced larger increases in house prices during the boom.

We continue to estimate the aggregate impact of introducing interest-only mortgages with the Synthetic Control Methodology (SCM) and several cross-country panel datasets. Our results indicate that the introduction of IO loans amplified the boom-bust pattern in Danish housing markets. Specifically, the introduction of IO loans during the 2000s caused Danish house prices (at the national level) to increase 35 percent relative to a carefully chosen control group of housing markets that also experienced a boom but for whom IO loans were not available. This increase accounts for 60 percent of house price growth between 2003Q4 and 2006Q4. In contrast, during the bust (2007Q1 2010Q1), Danish house prices fell 23 percent more than a counter-factual that also experienced a housing bust. We also examine the effects of the policy innovation on the cross-section of Danish cities. ${ }^{2}$ These results imply that the consequences of the IO loan policy are heterogeneous and vary based on local housing supply and house

\footnotetext{
${ }^{1}$ Andersen et al. (2012) show that Danish households with interest-only mortgages tend to take out a larger loan.

${ }^{2}$ Spatial patterns in housing markets are well established. See Sinai (2013) and Ferreira \& Gyourko (2012).
} 
price expectations at the time of the reform. If supply is unconstrained new supply should quickly lead prices to revert downwards. In inelastically supplied areas, such supply responses may be slower, and thus house prices may stay above some fundamental level for longer (Glaeser et al. , 2008). Consistent with this, the cross-sectional effect varies based on local housing supply, and we find that the effect of the reform is mainly concentrated in inelastically supplied areas.

Why did house prices increase so dramatically following the reform? The Danish evidence is consistent with a credit demand shift following the reform. As our model shows, introducing interest-only loans can actually lead to an increase in credit demand, even absent any changes in income. Interest-only mortgage does not preclude the household from saving in a different asset, and the increased liquidity could be used to increase consumption, pay down higher-interest debt or to save in higher-yielding assets such as stocks. Danish interest-only loans, combined with an institutional framework that allows for home-equity withdrawal and provides all borrowers legal right to refinance to take advantage of lower interest rates regardless of housing equity, resembles the optimal contract derived in Piskorski \& Tchistyi (2010). Piskorski and Tchistyi show that an option ARM (Adjustable Rate Mortgage) contract with an attached credit line, is an Pareto improvement over a traditional 30-year mortgage for both borrowers and lenders. The evidence is not consistent with a credit supply shift. While mortgage debt did increase following the reform, we believe that this was a movement along the credit supply curve, not a shift of the curve itself. We base this assertion on several facts. First, the fraction of income spent on interest payments is lower in 2004 and 2005 compared to the year prior to the reform. Additionally, there is no change in the income, wealth or age distribution of buyers, and the percentage of mortgage debt for the lowest quintile of income is stable across time. If anything, the income distribution shifts to the right (towards higher income) during the housing boom. There is no apparent decrease in borrower quality and no apparent shift in credit supply towards low-quality borrowers in the data. Second, non-performing loans, forced sales of homes and default rates all remained low throughout downturn 
in 2008, and are an order of magnitude lower than corresponding rates in the United States, even though the decline in house prices was of a similar magnitude in Denmark and the United States. Third, these facts match official government reports on bank lending activity and statements from the mortgage banks, which affirm that borrowers were evaluated on their ability to afford payments on a standard 30-year mortgage. If lending standards were unchanged following the reform, the increase in mortgage debt is not caused by a new group of households that were earlier denied credit. Moreover, it is also not likely that households purchased homes with IO mortgages with the intent of defaulting if prices declined. ${ }^{3}$ Full recourse mortgage debt removes the option to default if the value of mortgage debt exceeds housing values. If a home-owner defaults the bank can force a sale of the property and convert any residual debt into higher-interest bank debt.

This paper contributes to an important literature that aims to determine the origins of the recent housing boom and its subsequent collapse. Mian \& Sufi (2009) contend that an outward shift in the supply of credit to low quality borrowers was an important determinant of the recent boom. ${ }^{4}$ In contrast, Adelino et al. (2016) argue that there was no outward shift in credit, and that the housing boom was a demand-side phenomenon. ${ }^{5}$ Our work extends this literature in the following ways. First, we show financial innovation, in the form of new mortgage products, can cause an increase in the demand for credit, and that this increase in demand can have large effects on house prices. This is a different mechanism than the one emphasized in Adelino et al. (2016), who argue that home-buyers and lenders had high house price expectations and bought into expected increases in prices. ${ }^{6}$ Second, we show that this increase in demand occurs throughout the income distribution, consistent with recent research that has emphasized the importance of prime borrowers in the housing boom (Adelino et al. , 2016; Ferreira \& Gyourko, 2015). The implication of the results is that financial innovation is of primary importance for understanding the housing boom, but that

\footnotetext{
${ }^{3}$ See Barlevy \& Fisher (2011).

${ }^{4}$ See also Favara \& Imbs (2015) and Garmaise (2013).

${ }^{5}$ See alsoGerardi et al. (2010) and Ferreira \& Gyourko (2015).

${ }^{6}$ See Brueckner et al. (2016) on house price expectations and subprime borrowing.
} 
the effect of financial innovation is not necessarily limited to low-quality borrowers. As we show, financial innovation in the form of new mortgages are attractive for all borrowers, and financial innovation does not necessarily have to target worse quality borrowers to have an effect on house prices. The increased availability of IO loans in the US, triggered by financial innovation and shifts in credit supply, thus likely increased housing demand even among prime borrowers.

Overall, our results provide new insights into the origins of the housing boom and show how financial innovation and credit demand, even if they are directed towards prime borrowers, can amplify price swings. The findings may thus warrant a re-examination of the role of financial innovation for prime borrowers in the genesis of the US and global housing crisis.

\section{Theoretical Framework}

Here, we analyze the effects of amortization payments within two models. First, we treat the required amortization share as a policy parameter and thus exogenous in a two-asset model. Then, we consider a simpler one-asset model where the share paid into amortization is endogenous to determine optimal amortization payments in terms of model parameters. These two models allow us to concisely describe the role of amortization payments in a policy framework, and what factors affect households' choice of amortization payments. Generally, this class of models builds on two-asset models including those of Kaplan et al. (2014) and Kaplan \& Violante (2014).

\subsection{Model 1: The Amortization Share is Policy Parameter}

Consider a household that lives for periods $t=0,1,2$, consumes only during periods $t=1,2$, and makes a portfolio allocation decision during period $t=0$. In period $t=0$, the household allocates its initial endowment, $\omega$, between a liquid (safe) asset, $m_{1}$, that matures in period 1 and an illiquid asset, $a$, that matures in period $t=2$. The liquid asset is available again for purchase in period $t=1$ and matures in period $t=2\left(m_{2}\right)$. The household consumes all available funds in period 2 and cannot die 
with negative financial wealth.

As we want to study the role of amortization payments, we make the assumption that $a>\omega$. Thus, the household can purchase the illiquid asset with a down-payment equal to $a \cdot d$, where $d$ is the down-payment percentage and hence the household takes out a loan to purchase the illiquid asset. The amortization share is $s$. The one-period gross return on liquid asset is normalized to 1, the one-period gross return for the loan used to purchase the illiquid asset is $r$, and the two-period return on the illiquid asset is $R$. For simplicity, we assume that there is no discounting and no uncertainty and that $1<r^{2} \leq R$. We also assume that the household can only borrow by purchasing the illiquid asset, so that $m_{1} \geq 0$ and $m_{2} \geq 0$. Finally, the household earns labor income $y_{1}$ and $y_{2}$ in periods $t=1$ and $t=2$ respectively.

Utility in consumption in period $t=0$ is given by

$$
v_{0}=\max u\left(c_{1}\right)+u\left(c_{2}\right)
$$

where $u(\cdot)$ is twice continuously differentiable with $u^{\prime}>0$ and $u^{\prime \prime}<0$.

The resource constraint in period $t=0$ is

$$
a d+m_{1}=\omega
$$

and the budget constraints for periods $t=1$ and $t=2$ are

$$
c_{1}+m_{2}+\underbrace{(r-1)(1-d) a}_{\text {interest }}+\underbrace{s(1-d) a}_{\text {principal }}=y_{1}+m_{1}
$$

and

$$
c_{2}+\underbrace{r(1-s)(1-d) a}_{\text {interest plus principal }}=y_{2}+m_{2}+R a
$$

In period $t=1$, the household has potential expenditures consisting of consumption, the liquid asset that will mature in period $t=2$, interest on the debt used to purchase 
the illiquid asset, and any principal repayments. Income stems from the labor market and the liquid asset purchased in period $t=0$. During period $t=2$, the household has to pay off any remaining principal plus interest, but get income from labor as well as the liquid and illiquid assets.

In period $t=0$ the household solves the following optimization problem:

$$
\begin{gathered}
\max _{m_{1}, a} u\left(c_{1}\right)+u\left(c_{2}\right) \\
\text { s.t. } \\
c_{1}+m_{2}+(r-1)(1-d) a+s(1-d) a=y_{1}+m_{1} \\
c_{2}+r(1-s)(1-d) a=y_{2} \\
a \geq 0, m_{1} \geq 0
\end{gathered}
$$

Taking the first order condition (FOC) of the households problem at $t=0$ with respect to $a$, the FOC at $t=1$ with respect to $m_{2}$, and combining equations yields the following "long-run" Euler equation:

$$
u^{\prime}\left(c_{1}\right) \geq \bar{R} u^{\prime}\left(c_{2}\right)
$$

where

$$
\bar{R}=\left[\frac{R-r(1-s)(1-d)}{d+(1-d)(r-1+s)}\right]
$$

The numerator of $\bar{R}$ is the net period 2 return on the illiquid asset and the denominator is the portion of the illiquid asset that the household has paid for by the end of period 1 (down-payment percentage + interest + amortization share). Note that $\bar{R}$ is increasing in $s$. For a household optimizing at $t=0$, equation 5 states that $\bar{R}$ is the price of consuming at $t=1$ rather than $t=2$. Thus a decrease in the required share to be paid into amortization will lower the price of consumption at period $t=1$ relative to $t=2$, given that the household owns the illiquid asset. Intuitively, a decrease in $s$ lowers the period 2 net return (numerator of $\bar{R}$ ) while decreasing period 1 expenditures, allowing the household to better consumption smooth the income increase created by illiquid asset across periods 1 and 2 . 
Using the FOC with respect to $m_{2}$ from the optimization problem at $t=1$ and the fact that $c_{1} \leq c_{2}$ when $u\left(c_{1}\right) \geq u^{\prime}\left(c_{2}\right)$ yields

$$
m_{2}=\max \left\{\frac{y_{1}+\omega-y_{2}-a[2 d-1+s(1+r)(1-d)+R]}{2}, 0\right\}
$$

Here, an increase in $s$ leads to a reduction in $m_{2}$ as the household pays more in amortization. For simplicity, we assume that $u(c)$ has a constant elasticity of substitution utility with elasticity parameter $\sigma$. If $m_{2}$ is equal to zero (a Hand-to-Mouth (HtM) household (Kaplan et al. , 2014)), the household will purchase the asset $(a>0)$ when

$$
R>\left(\frac{y_{2}}{y_{1}+\omega}\right)^{1 / \sigma}[d+(1-d)(r-1+s)]+r(1-s)(1-d)
$$

Further, the right hand side of equation 8 is increasing in $s$ if

$$
\left(\frac{y_{2}}{y_{1}+\omega}\right)^{1 / \sigma}>r
$$

In other words, for HtM households, a decrease in the required share paid into amortization increases the probability of illiquid asset purchase as long as income growth, augmented by the inverse of intertemporal elasticity of substitution, is larger than the mortgage rate. Intuitively, congruent with Cocco (2013), HtM households are more likely to purchase the illiquid asset as $s$ drops since lower levels of $s$ allow households to smooth consumption while still owning the illiquid asset. This was also the Danish Government's rationale for the law change.

For non-HtM households $\left(m_{2}>0\right)$, equation 9 becomes

$$
\left(\frac{y_{2}+y_{1}+\omega}{y_{1}+\omega-y_{2}}\right)^{1 / \sigma}>r
$$

Here, for reasonable parameter values, and non-zero $y_{2}$, a decrease in $s$ will increase the probability that a non-HtM household purchases the illiquid asset, because a decline in $s$ lowers $\bar{R}$, and aids the household smoothing the gains of the illiquid asset over its 
lifetime.

\subsection{Model 2: The Amortization Share is Endogenous}

Next, we augment the above model and let $s$ be a choice variable at $t=1$. For simplicity, we eliminate the liquid asset. Taking the FOC of the household's period 1 maximization problem with respect to $s$ yields

$$
s \geq \frac{y_{1}-r y_{2}-a r R+a(1-d)\left(r^{2}-1\right)}{(1-d)\left(r^{2}-1\right)}
$$

The following testable predictions are immediately clear: (1) $s$ is increasing in $\left(y_{1}-\right.$ $\left.r y_{2}\right)$, so higher second period income growth, given the interest rate, will reduce the share that the household pays into amortization; and (2) $s$ is decreasing in $R$ and thus a higher return on the illiquid asset will induce the household to make lower amortization payments. The model also predicts that $s$ is decreasing in $r$, but the mortgage rate in our data unfortunately does not vary over the cross-section.

\section{Housing and Mortgage Markets}

The following section describe the housing market and mortgage system in Denmark and the sample countries. See Campbell (2013) for more information about mortgage market design, and Bäckman (2016) for more information about the Danish housing market.

\subsection{Mortgage Finance in Denmark}

The mortgage finance system in Denmark is highly rated internationally (Campbell, 2013). Similar to the United States, Danish mortgages have historically consisted of a long-term fixed rate mortgage without pre-payment penalties. Households can finance up to 80 percent of home purchases using mortgage loans with a legally mandated maximum maturity of 30 years, and can fund an additional 15 percent using higher interest bank debt. Denmark does not have a continuous credit-score system and there 
are no requirements on positive equity for refinancing. There are no pre-payment penalties, and households are legally allowed to refinance their mortgage loans to take advantage of lower interest-rates, provided the principal balance is not increased.

Mortgage credit in Denmark is extended to borrowers through specialized lenders called mortgage credit banks (henceforth mortgage banks), who act as intermediaries between borrowers and investors. These institutions face strict underwriting criteria that require them to assess the credit worthiness of all borrowers upon granting a mortgage, and they are prohibited from offering new products without regulatory and legal approval, which has limited the number of mortgage products available for households. Mortgage banks are required to assess both the value of the underlying property and the borrowers ability to afford mortgage payments (International Monetary Fund, 2011). After extending credit to borrowers, the proceeds from the loans are sold to investors in the form of mortgage bonds. The interest rate for borrowers is therefore set by the market for mortgage bonds. The mortgage banks is legally mandated to hold the mortgage bond on their balance sheet throughout the loan period, thereby retaining any credit risk. If a borrower defaults, the mortgage bank is required to replace the defaulting mortgage by one with similar characteristics. Mortgage bonds therefore face no credit risk, provided the issuing lender remains solvent, and the investors in mortgage bonds instead assume interest rate- and pre-payment risk. In over 200 years of operation, no mortgage bond has ever defaulted (Andersen et al. , 2014).

If a borrower defaults, the mortgage bank can trigger a forced sale of the underlying asset. Any residual claim is converted into an unsecured personal claim, where the interest rate is higher than the mortgage rate. In legal parlance, mortgage loans in Denmark are full recourse. This feature of the Danish mortgage system makes default unattractive for borrowers (see Ghent \& Kudlyak, 2011, for evidence on recourse laws and default from the United States) and default rates remained low throughout the boom and the bust. As we describe in more detail later, mortgage arrears peaked at 0.6 percent of outstanding amounts, and forced home sales remained low throughout the housing bust. Compare this to the United States, where mortgage default peaked 
above 10 percent. Further, personal bankruptcy in Denmark is difficult and does not necessarily reduce the debt burden.

In total, the mortgage system provide 1) originators with strong incentives to monitor borrowers during the underwriting process (Campbell, 2013); 2) strong incentives for the borrower to carefully assess the state of both their future income and the state of the housing market, and to not over-extend themselves; and 3) a low risk environment for investors in mortgage bonds. The design of the system combine to remove concerns over moral hazard in lending, excessive points and fees, low documentation loans, and limited monitoring of new borrowers during the Danish housing boom.

\subsection{Mortgage Reform in 2003}

Following a rapidly implemented law change, mortgage banks were allowed to offer a new type of mortgage product on October 1st, 2003. The law was introduced to the Danish parliament on March 12, 2003, and passed on June 4, 2003 with a large majority voting in favor of the proposal. The law change allowed mortgage banks to offer a form of interest-only loans, deferred amortization mortgages, where principal repayments could be postponed for up to 10 years, even though the full amount still had to be repaid over the 30-year contract. ${ }^{7}$ The intention of the government was to increase the flexibility of mortgage financing, thereby increasing affordability for cashconstrained households, such as students, young adults and households on temporary leave from the labor market. The expectation was that IO loans would be used as a temporary niche solution. Indeed, the government expected that penetration would be low, and that the reform would have no long-term impact on house prices. ${ }^{8}$ IO mortgages were only granted to households who could afford a standard 30-year fixed interest mortgage (Ministry of Economic and Business Affairs, 2007). Prior to 2007,

\footnotetext{
${ }^{7}$ The law technically allows the mortgage to have a ten-year interest-only period. Amortization payments can potentially be deferred forever by rolling over into a new mortgage contract after ten years, provided that the house value does not decrease. Danish media reported on this aspect of the new loans. See e.g. Politiken (2003).

${ }^{8}$ The law proposal includes a rationale the reform, along with the expected effects. The material is available in Danish at https://www.retsinformation.dk/Forms/R0710. aspx?id=91430.
} 
the interest rates and the fees collected by the mortgage credit institutions did not differ between mortgage products. Further, households understood the consequences of IO loans: In a 2011 survey of households with IO mortgages, 89 percent reported that they were "very well informed" or "well informed" on the implications of choosing IO mortgages (Association of Danish Mortgage Banks, 2011).

Even though an IO loan is considerably more expensive in total, the first year costs can be substantially reduced. Figure 2 plots the first-year cost for a 1 million DKK fixed-rate mortgage with (solid line) and without (dashed line) amortization payments. On October 2003, total payments could be reduced by approximately 13,000 DKK $(\$ 2,000$ USD) per year. For the average house buyer in Copenhagen during 2003, the difference in annual payments for a fixed rate mortgage amounts to 7 percent of annual disposable income, or 11 percent of annual income when comparing payments for a variable interest-rate mortgage. ${ }^{9}$

IO loans rapidly became a popular choice across all types of households. Figure 3 plots the outstanding mortgage amounts by loan type. Prior to the reform, nearly all mortgages were fixed interest with amortization payments, but this rapidly changed once IO mortgages were introduced. One year after the reform, 15 percent of all outstanding mortgages were IO loans. This number increased to 30 percent in 2005 and to 50 percent in 2010. Mortgage lending expanded rapidly following the reform, increasing by nearly 50 percent between 2003Q3 and 2007Q1. Nearly all of this growth is attributable to IO loans. Finally, figure 4 plots the geographical distribution of interest-only mortgages across Danish municipalities in 2012. Interest-only loans are concentrated in the Copenhagen area, in Northern Zealand and in the area around Aarhus.

\footnotetext{
${ }^{9}$ Calculations are based on an annuity schedule, where the total monthly cost is constant across the loan period. The reduction in monthly payments would higher with a straight amortization schedule. The average sales price in Copenhagen was 1.3 million DKK, the average disposable income for buyers was 204,575 DKK per year, and the average difference in payments from the introduction of IO loans to the end of 2003 for a 1 million DKK mortgage was 13,000 DKK for a fixed rate mortgage and 22,000 DKK for a variable interest mortgage. Assuming a down-payment of 20 percent, the savings as a percentage of disposable income is $13,000^{*} 1.3 * 0.8 / 204,575=6.7 \%$ for a fixed rate mortgage and $22,000 * 1.3 * 0.8 / 204,575=11.1 \%$ for a variable rate mortgage.
} 


\subsection{A Comparison of Mortgage Markets}

This section documents key institutional characteristics of mortgage markets, such as predominant loan types and usual length of mortgage contracts. Table 9 in appendix D summarizes key characteristics of mortgage markets for Canada, Denmark, Finland, Italy, Spain and the United States.

There is considerable heterogeneity in mortgage market design across countries, reflecting cultural differences and the institutional setting of the banking sector (Campbell, 2013). ${ }^{10}$ The typical loan term varies from 15 years in Italy and Spain, to 30 years in Denmark and the United States. Fixed interest mortgages are available in Canada, Denmark, Italy, and the United States, whereas variable interest loans are available in Canada, Denmark, Finland, Spain and the United States. Fixed interest loans are the predominant loan type in Denmark, Canada, Italy and the United States. The loan-to-value (LTV) ratio can exceed 80 percent in Canada, Denmark, Spain and the US. For all these countries except Spain, any mortgage with an LTV of over 80 percent incurs additional costs. ${ }^{11}$ Next, all countries except Canada allow mortgage interest deductions, and all countries in the sample have full recourse mortgages expect the United States. Denmark, Canada and Finland allows for equity withdrawal.

We report whether IO mortgages were available in the sample country. IO mortgages were legal and prevalent the United States over our sample period. In all other countries, IO mortgages were either not available or were accompanied by a repayment vehicle. In countries where IO loans are accompanied by a repayment vehicle there are no amortization requirements per se, but households are legally required to save in another savings vehicle for the purpose of repaying the mortgage debt at maturity. Hence, we consider such countries as non-IO counties. In Finland, IO mortgages have to be accompanied by a repayment vehicle where households save in some other asset,

\footnotetext{
${ }^{10}$ For a more detailed overview, see e.g. ECB (2003); Campbell (2013); International Monetary Fund (2011); Scanlon et al. (2008).

${ }^{11}$ In Denmark, a households can borrow an additional 15 percent using higher interest bank loans. In the US and Canada mortgages with an LTV over 80 percent are subject to mortgage insurance (Crawford et al. , 2013).
} 
such as stocks or bonds, making them relatively conservative in nature. Additionally, Finish IO mortgages accounted for less than 3 percent of outstanding mortgages in 2005. Italian IO mortgages similarly have to be accompanied by an investment vehicle. Spain legalized IO mortgages in April 2006, but as Scanlon et al. (2008) report only a few Spanish banks offered these mortgages in 2008. IO mortgages have never been formally allowed in Canada. These non-IO countries constitute our control group. Last, as noted above, IO loans were introduced to Denmark in 2003.

House price growth was high for all countries between 1998Q1 and 2002Q4. Denmark's increase of 32 percent is very close to the observed increase in Canada, Finland and Italy. In figure 15 in appendix E, we plot the growth in private credit flows, 10-year government bond yields, mortgage rates, and house prices for our Canada, Denmark, Finland, Italy, and Spain. ${ }^{12}$ The figure indicates that (1) private credit did not disproportionately flow more to Denmark than to any other country; (2) mortgage and interest rates were highly correlated across countries prior to the housing bust; and (3) house price growth was similar across countries between 1998 and 2003. ${ }^{13}$ As private credit flows did not disproportionately flow to Denmark, and as interest and mortgage rates were similar across our sample, we can abstract from international changes in credit supply as a potential explanation for our Synthetic Control results below in section 6.2. To clarify, we do not believe that there is a reason that something akin to the global savings glut hypothesis of Bernanke (2007) would affect Denmark dis-proportionally to the other countries in the sample.

Finally, as local Canadian housing markets will serve as our control group in our city-level analysis, we provide a detailed comparison between the Canadian and Danish labor and housing markets. Although Denmark is often compared to the United States (Campbell, 2013; Andersen et al. , 2014), the Danish housing market may more closely resemble that of Canada. Neither Denmark nor Canada experienced a deterioration of lending standards during the 2000s housing boom. In Canada, only 30

\footnotetext{
${ }^{12}$ Mortgage rates over our sample were only available for Canada and Denmark.

${ }^{13}$ The notable exception is Spain which experienced large private credit flows and large house price increases.
} 
percent of mortgages are securitized and these securities are explicitly guaranteed by the government owned Canada Housing and Mortgage Corporation (Kiff, 2009). Similarly, Danish mortgage banks retain the credit risk associated with mortgage bonds and hence Danish mortgage bonds also carry little default risk.

The Danish labor market is characterized by a generous safety net, combined with active labor market policies (Andersen, 2012). While the safety net in Canada are less generous than in Denmark, it is certainly more prominent than in the United States. Furthermore, GDP per capita, the labor force participation rate, and trade as a percentage of GDP are all closely aligned in Denmark and Canada, along with health expenditure per capita as a percentage of GDP.

In total, recourse laws, the social security net and the conservative nature of the Canadian and Danish housing finance systems makes Canadian cities an apt control group in our assessment of the introduction of IO loans to Denmark in 2003. ${ }^{14}$

\section{Data}

We first collect high-quality micro-data from Statistics Denmark on the full population of households. Our dataset covers property transactions as well as detailed demographic and economic information on the universe of all Danish households from 1994 to 2010. We match data on property transactions to each household using ownership registers. Individual- and household-level variables include household level demographic information, along with financial information such as financial wealth and household income. Unfortunately there is no loan-level data that would allow us to identify interest-only loans from standard mortgages. For a more detailed description of the data and the sources, see Bäckman (2016).

Second, we assemble a dataset of international and city-level variable to estimate the impact on the aggregate level. We consider data at both the quarterly and monthly

\footnotetext{
${ }^{14}$ Also note that Canada pursued a number of pro-cyclical housing market policies during the 2000s and countercyclical policies after 2008. None of these polices are related to IO loans, but will make our results more conservative in nature if they had any impact on the Canadian housing market. See Krznar \& Morsink (2014) and Kiff (2009) for more details.
} 
periodicities. Our aim is to estimate the impact of IO loans in Denmark where the donor pool of potential control units consists of countries where IO loans were not available. Unfortunately, IO loans were pervasive across many European countries and the United States, limiting the number of potential control units. The donor pool of potential control units consists of countries where IO loans were not available. Our set of non-IO loan countries includes Canada, Finland, Italy, and Spain. For each country, our data include house prices from the BIS, GDP per capita, durable consumption per capita, and the growth in private credit flows to the non-financial sector. All variables are in real terms. ${ }^{15}$ House prices capture dynamics in the housing market, GDP per capita and durable consumption per capita capture national-level economic activity, and the growth in credit flows measures changes in credit. These data range from 1998Q1 to 2012Q1. In addition to these time series, we calculate time-varying housing market return volatility from a fitted $\operatorname{GARCH}(1,1)$ model and the pre-treatment period (1998Q1 - 2002Q4) house price growth. Appendix C contains a complete list of all variables, their sources, different permutations of the data, and the associated number of potential Synthetic Control units.

We also build a city-level dataset where we compare Danish and Canadian cities, as Canada is the only non-IO country where housing data is available across cities. $^{16}$ The data available at the city-level include house prices, fitted time-varying housing return volatility estimated from a $\operatorname{GARCH}(1,1)$ model, the pre-treatment house price growth, population in 2001, median income in 2001, and the unemployment rate in 2001. ${ }^{17}$ Canadian house price indices are available from both Statistics Canada and from Teranet. The house price data from Statistics Canada are based on new home construction and are available for 21 cities; while those from Teranet are repeat-sales

\footnotetext{
${ }^{15}$ GDP per capita is aggregate real, seasonally adjusted GDP divided by total population; and real, seasonally-adjusted durable consumption data are transformed into Euros per capita. Currency conversion data date back to 1998 when Euro-area countries fixed their currencies. The currency data are from Eurostat.

${ }^{16}$ We use house price data for the following Danish regions: CopenhagenCity, CopenhagenSurroundings, EasternJutland, EasternZealand, Fyn, NorthernJutland, NorthernZealand, SouthernJutland, WesternJutland, WestSouthZealand.

${ }^{17}$ Income, population, unemployment data are from Statistics Canada and Statistics Denmark, respectively.
} 
indices estimated in a fashion similar to the Case-Shiller indices in the US and cover 11 cities. $^{18}$ These indices are constructed to ensure comparability - we closely follow the Teranet methodology when we construct Danish repeat-sales indices. ${ }^{19}$ In our main results, we exclude Canadian cities that experienced a resource boom during the sample period from the donor pool. ${ }^{20}$ The inclusion of Canadian resource cities does not qualitatively affect our results.

We subtract all pre-treatment macro predictor variables (unemployment rate, median income, and population density) by their country-level means and divide by their country-level standard deviations. Subtracting each macro predictor variable by its country-level mean is akin to including country fixed effects in panel models and thus allows us to account for unobserved heterogeneity, such as institutional or labor market differences, across countries. Further, dividing each predictor variable by its standard deviation creates a unit-less measure for easy comparison across countries. In our main results below, we report our findings for the "standardized" (Std) macro data. A robustness check confirms that our findings are similar when we use the unadjusted macro data.

\section{Econometric Methodology}

To estimate the impact of IO mortgages on housing markets during the recent boom, we use the Synthetic Control Method (SCM) of Abadie \& Gardeazabal (2003) and Abadie et al. (2010). The SCM implements a data-driven procedure for comparative casestudies that allows us to estimate the causal impact of a policy intervention occurring at the aggregate level. Overall, the advantages of the SCM are manifold. ${ }^{21}$ Specifically, Abadie et al. (2010) show that the SCM generalizes the fixed effects (difference-

\footnotetext{
${ }^{18}$ Teranet cities include Calgary, Edmonton, Halifax, Hamilton, Montreal, OttawaGatineau, Quebec City, Toronto, Vancouver, Victoria, Victoria, and Winnipeg. See http://www.housepriceindex.ca/default.aspx.

${ }^{19}$ Our results are also robust to the use of the HPIs available from Statistics Canada and an alternate set of HPIs provided by Statistics Denmark.

${ }^{20}$ The cities in our sample that experienced a resource boom include Calgary, Edmonton, Regina, Saskatoon, and Winnipeg. See International Monetary Fund (2010).

${ }^{21}$ See Abadie et al. (2010) and Billmeier \& Nannicini (2013) for more details.
} 
in-differences) estimator as the unobserved unit-specific heterogeneity can vary over time.

Hence, the SCM is well-suited to evaluate the effects of the introduction of IO mortgages. We construct a Synthetic Control unit from a convex combination of available control units that best represents the most relevant characteristics of the treated unit during the period prior to the policy intervention. Then in the wake of the policy, the so-called post-policy intervention period, the path of the Synthetic Control unit represents the counter-factual situation of the treated unit in absence of the policy change. The causal impact of the policy is thus calculated by comparing the treated unit to its Synthetic counterpart.

Inferential techniques within the SCM can be carried out through placebo studies. A placebo study iteratively assigns the treatment to all other units of the donor pool. ${ }^{22}$ Then we compare the causal impact of the treatment in this placebo experiment, the placebo effect, to the causal impact for the unit where the intervention occurred. Iteratively applying the treatment to random members of the control group and retaining the subsequent placebo effects is comparable to a permutation test where a test statistic is calculated under random permutations of the treatment and control group. The magnitude and rarity of the treatment effect can then be assessed relative to the set of estimated placebo effects. We apply the treatment to all members of the control group and this will yield our so-called permutation test. ${ }^{23}$ The permutation test will then be used for inference.

\section{Results}

In this section, we examine how the Danish housing market changed following the reform, and how the characteristics of Danish home-buyers changed following the reform.

\footnotetext{
${ }^{22}$ Placebo studies can also be carried out by assigning the treatment to a random point in time. In the results below, we follow the literature and assign the treatment to the control units. Assigning the treatment to other time periods also supports the causal interpretation of our results.

${ }^{23}$ As in Abadie et al. (2010, 2011) we will discard any placebo studies where the mean squared prediction error during the pre-intervention period between treated unit and its synthetic control in the placebo experiment is more than five times larger than that for the observed experiment.
} 
We start by showing that there was an increase in the number of transactions following the reform, and show among which groups transactions increased the most.

\subsection{Results - Micro-Level Effects}

We use data on the full population of Danish households to investigate how the housing market was affected by the introduction of interest-only mortgages. Table 1 estimates a linear probability model of the probability of buying, where the dependent variable is a dummy equal to one if the household purchases a property, and zero otherwise. The sample consists of the full population of households in 2002 and 2004; the year prior to and the first full year following the introduction of IO loans. The variable of interest is Post Reform, a dummy equal to one in year 2004 and zero otherwise, and interactions between Post Reform and various other variables. All columns include household and municipality-specific controls and region dummies.

Overall, table 1 shows that there was an increase in the probability of buying in 2004 compared to 2002, even after including several household- and municipality-level control variables. Column 1 shows that the increase between 2002 and 2004 in the probability of buying was positive and significant. Columns 2-5 interacts the Post Reform dummy with select variables to provide evidence on which groups had the largest increase in the probability of buying. Column 2 interacts Post Reform with a dummy equal to one for households living in municipalities that later experienced a boom. ${ }^{24}$ The positive coefficient on the interaction between boom and Post Reform shows that the increase in demand following the reform was larger in municipalities that later experienced a boom. A similar pattern is observed in column 3, which shows that areas with more inelastic housing supply experienced a larger increase in the probability of buying. In line with the predictions from the model, the coefficients on income growth between year $t$ and $t-1$ and between year $t+1$ and $t$ (column 4 and 5) are positive and significant. Furthermore, column 6 shows that the effect of income growth was not driven by HtM households.

\footnotetext{
${ }^{24}$ The municipalities in question are those surrounding Copenhagen, Aarhus and Odense.
} 
To investigate the prediction from the model that IO loan use is related to future income growth, we use data on reported IO loan penetration for Danish municipalities made available in a Danish newspaper article from 2012 (Politiken, 2012). Note that this is the only cross-sectional data on IO loans that is publicly available, but as the IO loan term in Denmark is ten years the data should include a large number of IO loans originated just after the policy date. The data was provided to the newspaper by one of the mortgage credit bank (Realkredit Danmark), and covers their customer base. Recall from Figure 4 that IO loans are widely used in the Copenhagen region and on Zealand, with IO loan penetration reaching over 60 percent in some areas. These figures are consistent with those from the London or California housing markets and indicate that IO loans were popular with a large portion of buyers in boom markets. Further, figure 5 shows the scatter plot of the IO loan penetration versus pre-treatment house price growth in (a), and the IO penetration versus income growth for buyers in (b) across Danish municipalities. The corresponding regression estimates are in table $2 .{ }^{25}$ The penetration is higher in areas with higher income growth, and increase with higher pre-treatment house price growth. A 1 percentage point increase in income growth increases the IO loan penetration by 1.22 percentage points. Using lagged house price growth as a proxy for house price growth expectations, as in Glaeser \& Nathanson (2015), Brueckner et al. (2012), DellAriccia et al. (2012), and Case et al. (2012), we find that the penetration of IO loans is significantly larger in housing markets with higher pre-treatment house price growth expectations. The $R^{2}$ for this regression is 0.245, indicating that pre-treatment house price growth expectations explain a sizable portion of the variation in IO loan penetration in 2012. Note that the results in table 2 are consistent with the results in table 1 . These findings are particularly noteworthy given the long time lag between the variables and are consistent with the prediction from the model that high income growth and higher expected returns on the illiquid asset increases the value of using an IO loan.

\footnotetext{
${ }^{25}$ We only include 93 municipalities in the regression, due to missing data on house prices and a low number of inhabitants.
} 


\subsection{Results - Aggregate Level}

In the following sections, we employ the SCM using international and city-level data to estimate the impact of IO loans during the 2000s housing boom. To start, data at the highest level of aggregation, the country-level, are used to assess the impact of IO loans during the 2000s boom and its aftermath within the SCM framework. In the international sample Denmark is the treated unit, and the donor pool consists of all other countries. Similarly, for the city-level results Danish regions are the treated unit, and the donor pool consists of Canadian cities. As noted above, we only include non-IO countries in the donor pool.

We begin by estimating the impact of the policy in Denmark and then we conduct placebo experiments where we iteratively apply the treatment to members of the donor pool in a permutation test. The pre-treatment period used to implement the SCM algorithm ranges from 1998Q1 to 2002Q4 as the policy was announced in 2003Q1. The implementation date for the policy was 2003Q4.

Table 3 shows the contribution of each unit in the donor pool to the Synthetic Control (for brevity, only countries with positive weight are listed), table 4 shows the average pre-treatment predictor values for Denmark, its Synthetic Control, and the sample average, and table 5 shows the estimated effects and the root mean-squared forecast error (RMSFE).

Overall, we believe that the Synthetic Control provide a good match for both Denmark and for the Danish cities. To begin, we estimate the effect with country-level data. The treated unit is Denmark, the outcome variable is the BIS house price index, and as we can see in table 3, Finland receives all of the weight, while Canada, Italy, and Spain receive no weight. The results in the top panel of table 4 indicate that Denmark is nearly identical to its Synthetic Control for the key pre-treatment predictor variables, house prices and pre-treatment house price growth. The pre-treatment house price growth, for example, is 31.65 percent for Denmark and 29.88 percent for the Synthetic

Control. Moreover, the Synthetic Control Unit represents a much closer match to 
Denmark relative to the sample average for most of the other housing and macro variables including $\operatorname{GARCH}(1,1)$ volatility, GDP per capita, and private credit flows. To further highlight the closeness of the Synthetic match, we print the root meansquared forecast error (RMSFE) of the Synthetic Control relative to Denmark for house prices over the pre-treatment period in panel 1 of table 5 . The RMSFE over the whole pre-treatment period is 15.98 and thus the average RMSFE per quarter is just 0.799. In comparison, the quarterly standard deviation of Danish house prices over the pre-treatment period is 9.73; implying that the average RMSFE per quarter is less than one-tenth of the quarterly pre-treatment standard deviation. Altogether, the SCM algorithm appears to aptly build the control unit based on pre-treatment data. Note that if Finland receives all the weight, this implies that Finland represents the best possible match for Denmark. This is similar to letting an algorithm chose the best control group for a difference-in-difference estimation.

Further, we reduce the geography of our data and conduct the SCM analysis at the citylevel. The donor pool consists of Canadian non-resource (coastal) cities for which the Teranet repeat-sales house price indices are available. ${ }^{26}$ We apply the SCM approach iteratively using the 10 Danish cities as the treated unit. ${ }^{27}$ Figure 14 in Appendix E provide a map of Denmark, indicating the location of Copenhagen and the major islands of Denmark.

As seen in the second panel of table 3, the Synthetic Control Units for the Danish cities largely consist of Canadian cities in the Ontario province. For example, the Synthetic match for CopenhagenCity is Ottawa-Gatineau, while that for CopenhagenSurroundings, Copenhagen's Suburban area, is 86 percent Ottawa-Gatineau and 14 percent Toronto. In general, we view these matches as reasonable since the OttawaGatineau region is Canada's capital city and Toronto is the largest city in Canada

\footnotetext{
${ }^{26}$ These cities are Halifax, Hamilton, Montreal, Ottawa-Gatineau, Quebec City, Toronto, Vancouver, and Victoria. In robustness checks, we expand the donor pool to cover all major Canadian cities.

${ }^{27}$ These Danish cities are CopenhagenCity, CopenhagenSurroundings, NorthernZealand, EasternZealand, EasternJutland, Fyn, WestSouthZealand, SouthernJutland, NorthernJutland, and WesternJutland.
} 
with a substantial suburban component. Further, the respective Synthetic Controls provide a much better match for CopenhagenCity and CopenhagenSurroundings than the sample average for the average pre-treatment predictor values in panels 2 and 3 of table 4. For example, the pre-treatment house price growth for CopenhagenSurroundings is 29.75 percent and that for its Synthetic is 31.78. In marked contrast, the average pre-treatment house price growth across Canadian cities is just 23.33 percent. The appropriateness of the match is also highlighted in the low RMSFE values in Table 5. The largest RMSFE occurs when CopenhagenCity is the treated unit with a value of 42.14. Yet even for CopenhagenCity the RMFSE is small in magnitude. Given the monthly periodicity of the data, the average RMSFE per month during the pre-treatment period is 0.90 . In comparison the monthly standard deviation of CopenhagenCity house prices during the pre-treatment period is 12.56 . Hence, the average RMSFE per month is less than one-tenth of the monthly standard deviation. The RMSFEs over the pre-treatment period for the other cities are all small and less than 10 in magnitude.

We illustrate the effect for the international sample in figure 6. The plot in the top-left panel of figure 6 presents the path of Denmark's house prices versus the sample average, while the plot in the top-right panel shows the path of house prices for Denmark versus the Synthetic Control. In the figure, the red-dashed, vertical line is the IO loan policy announcement date (2003Q1) and the blue solid line is the policy implementation date (2003Q4). Overall, the Synthetic Control provides a much better pre-implementation period match for Danish house prices relative to the sample average: Between 1998 and 2003Q4 house prices for Denmark and its Synthetic counterpart move in lockstep, while house prices for the sample average deviate noticeably from those for Denmark starting in 2002. Once IO loans are introduced, Danish house prices diverge dramatically from those of its Synthetic Control. As evinced by plot in the top-right panel of figure 6, by 2006 Danish house prices had more than doubled from their 1998 starting point, whereas those for Denmark's Synthetic had only increased by 65 percent. We plot the Gap between Danish house prices and the Synthetic Control in the bottom- 
left panel of figure 6 . The dotted lines represent the largest estimated placebo effect for each period from the permutation test in the bottom-right panel of the figure. Together, the Gap and Permutation plots highlight magnitude and rarity of the estimated effect: After the introduction of the policy, house prices increased substantially in Denmark and this appreciation is unparalleled relative to all other placebo effects. The uniqueness of the estimated treatment effect, relative to those from placebo experiments, supports a causal interpretation of the results. Note that house prices for Denmark's Synthetic Unit also increased markedly during the 2000s, which indicates that that Denmark would most likely have experienced an increase in house prices after 2003 even in the absence of any policy change. Hence, the introduction of IO loans amplified the ascension of house prices in Denmark relative to the counterfactual that also experienced strong house price growth.

The numerical estimates of the impact of the policy are listed in panel 1 of table 5 . The table shows the Gap in house price growth between Denmark and its Synthetic during the boom period (2003Q4 - 2006Q4), the bust period (2007Q1 - 2010Q1), and the ratio of the Gap to total house price growth for Denmark over the boom and bust periods. In the table, asterisks represent estimates for house price growth that are larger than all placebo effects. ${ }^{28}$ First, the Gap in house price growth during the boom was 35.80 percent, an estimate that is larger than all placebo effects. Hence, due to the introduction of the IO loans, Danish house prices grew an extra 36 percent compared to a counterfactual that also experienced substantial house price growth over the sample period. Additionally, the left column in the far-right panel table indicates that the IO loan policy explains 62 percent of the house price growth in Denmark between 2003Q4 - 2006Q4. Therefore, the majority of house price appreciation during the boom is due to the introduction of IO loans.

However, the effect was not uniform across Denmark. Figure 7 plots the results for CopenhagenSurroundings, the suburban area around Copenhagen. Figure 16 in ap-

\footnotetext{
${ }^{28}$ Specifically, for the boom (bust) period, an asterisk indicates that the effect for the treated unit is larger(smaller) than all estimated placebo effects.
} 
pendix E displays the permutation test plots for all Danish cities, and shows considerable heterogeneity in the estimated effect. After the IO loan policy is implemented in Denmark, house prices in CopenhagenSurroundings diverge markedly from the Synthetic Control, similarly to the pattern observed for Denmark as a whole. ${ }^{29}$ From the start of the sample to the peak of the boom (1999M04 to 2006M07), house prices in CopenhagenSurroundings increased 127 percent, whereas those for the Synthetic increased only 62 percent. The two plots in the bottom of the figure show that this increase in house prices is both rare and extremely large in magnitude. At the peak of the housing boom (2006M07), the Gap between CopenhagenSurroundings and its Synthetic, the estimated effect, is more than twice as large as that for largest estimated placebo effect. Together, the plots in figure 7 indicate that the introduction of IO loans notably changed the dynamics of the CopenhagenSurroundings housing market, amplifying the boom that subsequently reversed during the bust. The second panel of table 5, however, shows that while the introduction of IO loans had a substantial impact in CopenhagenCity, CopenhagenSurroundings, EasternZealand, and NorthernZealand, other areas did not experience a boom related to IO loan use. During the boom the introduction of IO loans led to an increase in house prices of over 50 percent in CopenhagenCity, but just 8 percent in NorthernJutland. Further, in other cities, such as Fyn and NorthernJutland, there was almost no change in house prices due to the introduction of IO loans. These heterogeneous effects lead to large differences in the contribution of the treatment effect to the total growth in house prices. The Gap/Path ratio indicates the that the introduction of IO loans accounts for at least 70 percent of the growth in house prices in CopenhagenCity, CopenhagenSurroundings, and NorthernZealand, but for approximately zero of the growth in several other areas.

Finally, Danish house prices plunged during the bust. After 2006 housing returns started to wane before diving markedly in 2008. By 2010, the level of Danish house

\footnotetext{
${ }^{29}$ Note that the Teranet and Danish Repeat-Sales house prices indices are reported as a threemonth moving average. So, there is a small delay between the implementation of the IO loan policy and an increase in house prices in CopenhagenSurroundings.
} 
prices returned to match its Synthetic Control, erasing all relative gains accumulated during the boom. In total, from 2007Q1 to 2010Q1 (the bust period), house prices in Denmark fell an extra 23.36 percent compared to the Synthetic, an estimate that is larger in magnitude than all estimated placebo effects. Furthermore, house price fell more than the Synthetic Control in several areas that did not experience an increase in prices due to IO-loans in the boom. The above results imply that the introduction of IO loans amplified the boom-bust pattern in house prices.

\subsection{Helsinki Placebo Test}

In the previous section, we used Canadian cities to construct a Synthetic Control unit for local Danish housing markets. One potential concern with this approach is that a combination of Canadian cities may not yield an appropriate match for a Northern European housing market after 2003 had the IO loan policy not been implemented. To address this issue, we conduct a placebo experiment where we let the treated unit be Helsinki, the capital of Finland. Recall that in section 6.2 we found that Finland was a close match for Denmark during the pre-treatment period. Thus, we can use Helsinki to estimate the placebo effect when the treatment is applied to a similar Northern European capital city housing market. Because the house price index for Helsinki is quarterly, we transform the Teranet house price indices to the quarterly frequency by retaining the last value for the house price index in each quarter. The data run from 1999Q2 to 2008Q4. For this analysis, the outcome variable is house prices and the predictor variables include house prices, $\operatorname{GARCH}(1,1)$ housing return volatility, and the pre-treatment house price growth (1999Q2 - 2002Q4). The results are in panel 3 of tables 3 and 5 and figure 17 of appendix E. The Synthetic Control for Helsinki is made up of 57 percent Halifax and 41 percent OttawaGatineau and the top-right plot in figure 17 suggests that the Synthetic yields an appropriate match for Helsinki, especially after 2000. Indeed, the RMSFE during the pre-treatment period is small in magnitude at 27.19. Next, after the IO loan treatment is applied to Helsinki in 2003, there is in no divergence in the path in house prices between Helsinki and its 
Synthetic. As seen in the bottom two panels of figure 17 in appendix E, the estimated Gap for Helsinki is small in magnitude and in line with the other estimated placebo effects. In total, a combination of Canadian cities closely approximates the path of prices in a non-IO Northern European housing market after 2003.

\section{$7 \quad$ Evaluating Alternative Explanations}

In this section we evaluate alternative explanations for the Danish housing boom, and show that the results are not consistent with an shift of credit supply nor with neither increased speculation in housing.

First, we want to be clear that we believe that the introduction of IO-loans did lead to an increase in credit. However, the evidence is more consistent with a move along the credit supply curve, not of a shift of the credit supply curve itself. Such a shift would occur if banks were more willing to lend to consumer for a given level of income or wealth. For example, shifts could occur due to increased securitization, greater risk diversification, an increase in the value of implicit government insurance, increased government intervention in the mortgage market, or greater moral hazard on the behalf of originators. Recall that many of these explanations are limited by Danish mortgage market design (Campbell, 2013). Mortgage banks are legally obliged to retain credit risk and cannot sell this risk on to investors, so greater moral hazard on behalf of originators is ruled out by design. There is no government intervention in the mortgage market and no government insurance of mortgages. Further, official reports state that credit was extended to borrowers based on their ability to afford a 30-year fixed mortgage (Ministry of Economic and Business Affairs, 2007), and ex post outcomes such as forced home sales, non-performing loans and mortgage defaults remained low throughout the housing market downturn and the financial crisis. Figure 8 show mortgage arrear as a percentage of outstanding mortgage debt, and the number of homes repossessed by mortgage banks. Mortgage arrears shows the percentage of loans where a large share of total payments have not been met 3.5 months after the latest due date, which peaked at 0.57 percent in Denmark (Association of Danish Mortgage 
Banks, 2016). Mortgage impairments peaked at 0.2 percent of outstanding mortgages (Rangvid et al. , 2013), a rate which the mortgage banks were able to cover themselves, and government intervention was not required. In comparison, delinquency rates on single-family residential mortgages peaked at 10 percent, and non-performing loans to gross loans peaked at slightly below 5 percent in the United States (Board of Governors of the Federal Reserve System (US), 2016; World Bank, 2016).

Furthermore, to examine the claim by mortgage banks that borrowers were evaluated on their ability to repay the standard 30-year mortgage, we compare the distribution of income, financial wealth and mortgage payments as a percentage of income for all house-buyers in each year following the reform to the distribution in 2002. The results are in figure 9-11. For ease of exposition, each plot shows the distribution of each variable in 2002 (black, solid line) and in 2003, 2004, 2005, or 2006 (red, dashed line). Each graph includes a Kolgomorov-Smirnov test for equality of distribution on the right. There is no shift in the distribution towards lower income or wealth, and the distribution of mortgage payments to income shows that buyers were lessrisky in 2004 and 2005 compared to buyers in 2002. Instead there is a statistically significant shift towards the right in figure 9 and 10. In figure 11 buyers have lower mortgage payments to income in 2004 and 2005 than in 2002, showing no evidence that households were of worse quality. Therefore, after the policy change, mortgage credit did not disproportionately flow to lower quality borrowers. In 2005 and 2006, we do see a slight rightward movement in the income and financial wealth distributions. This small shift is in line with our expectations as houses were more expensive in 2005 and 2006 at the peak boom.

To further examine the credit supply hypothesis, we plot the fraction of total mortgage debt held by each income quintile over time. If there was a shift in credit supply, we should see a shift towards low income borrowers in the data. Figure 13 plots the fraction of total mortgage debt held by each income quintile, which is essentially unchanged over time. Low-income borrowers did not expand their holdings of mortgage debt following the reform. In panel (a) we plot results for all households, whereas panel 
(b) only includes households who buy in the given year. ${ }^{30}$ For both panels, the results are very similar - following the reform, we see no evidence that low income borrowers took on a larger fraction of the total debt. ${ }^{31}$

\section{Conclusion}

In this paper, we use micro- and aggregate-level data to assess the impact of IO loan availability during the 2000s on both the micro and aggregate level. Our results indicate that the introduction of IO loans in Denmark amplified the boom-bust pattern in housing: After the introduction of IO loans, the Danish housing market became much more volatile and speculative in nature. Indeed, due to IO loan availability, house prices jumped an extra 35 percent during the boom compared to a counterfactual that also experienced a housing boom but for which IO loans were not available. Further, IO mortgage availability contributed 60 percent to the increase in Danish house prices between 2003Q4 and 2006Q4. Subsequently, during the bust, Danish house prices reversed and dropped an additional 23 percent due to IO loans. These results cannot be explained by a change in borrower quality as lending standards or borrower quality did not change in Denmark during the 2000s. Further, while the effects of IO loans on housing markets are rare and large in magnitude compared to estimated placebo effects, they are heterogeneous across local housing markets. Specifically, the impact of the policy change is magnified in housing markets with higher pre-treatment house price growth expectations markets that experienced higher IO loan penetration and substantial house price appreciation during the 2000s.

Altogether, these findings are consistent with a shift in demand for credit following the reform, as the supply of credit did not shift. The results are in line with the predictions from the theoretical model, where a reduction in required amortization payment increases the ability of households to smooth consumption, which in turn increases

\footnotetext{
${ }^{30}$ Recall that there are no pre-payment penalties for refinancing, and that we could expect that low-income households refinanced into interest-only mortgages, even if they did not purchase a new property.

${ }^{31}$ Note that due to third-party reporting of income and wealth data, there are no concerns regarding misrepresented or fraudulent data in the calculation of these figures. See Mian \& Sufi (2015).
} 
their willingness to purchase housing. These results have important implications for other countries including the United States where IO loans were widely available. For example, a conservative back of the envelope application of our estimates to California, where IO loans made up nearly half of all new mortgages in 2004, indicates that IO loan availability led to an additional 54 percent increase in California house prices between 2002Q1 and 2006Q4. ${ }^{32}$ Last, given the depth of the Great Recession, the implications of our findings are wide reaching and suggest that policymakers should be aware of how new mortgage products can drive housing cycles even in the absence of a deterioration in borrower quality.

${ }^{32}$ FRED Series ID CASTHPI. Here, we assume that IO loan availability contributed 56 to the increase in house prices, the median of cross-sectional estimates across Danish cities. 


\section{References}

Abadie, Alberto, \& Gardeazabal, Javier. 2003. The economic costs of conflict: A case study of the Basque Country. American economic review, 113-132. 17

Abadie, Alberto, Diamond, Alexis, \& Hainmueller, Jens. 2010. Synthetic control methods for comparative case studies: Estimating the effect of Californias tobacco control program. Journal of the American Statistical Association, 105(490). 17, 18

Abadie, Alberto, Diamond, Alexis, \& Hainmueller, Jens. 2011. Synth: An r package for synthetic control methods in comparative case studies. Journal of Statistical Software, 42(13). 18

Adelino, Manuel, Schoar, Antoinette, \& Severino, Felipe. 2016. Loan Originations and Defaults in the Mortgage Crisis: The Role of the Middle Class. Review of Financial Studies. 4

Andersen, Asger Lau, Christensen, Anders Møller, Economics, Charlotte Duus, \& Kaarup, Ri. 2012. Danish Families' Financial Robustness, Variable Rates and Deferred Amortisation. Danmarks Nationalbank Monetary Review 4th Quarter Part. 2

Andersen, Steffen, Campbell, John Y, Nielsen, Kasper Meisner, \& Ramadorai, Tarun. 2014. Inattention and inertia in household finance: Evidence from the Danish mortgage market. Available at SSRN 2463575. 10, 14

Andersen, Torben M. 2012. A flexicurity labour market in the great recession: the case of Denmark. De Economist, 160(2), 117-140. 15

Association of Danish Mortgage Banks. 2011. Boligejerne har styr pa deres afdragsfrie realkreditlan. 12

Association of Danish Mortgage Banks. 2016. Mortgage Arrears. retrieved from the Association of Danish Mortgage Banks; http://www.realkreditraadet.dk/en/statistics/arrears. Accessed: August 18, 2016. 27

Bäckman, Claes. 2016. Examining the Housing Boom in Denmark. 9, 15

Barlevy, Gadi, \& Fisher, Jonas DM. 2011. Mortgage choices and housing speculation. 4

Bernanke, Ben. 2007. Global imbalances: recent developments and prospects. Bundesbank Lecture speech, September. 14

Billmeier, Andreas, \& Nannicini, Tommaso. 2013. Assessing economic liberalization episodes: A synthetic control approach. Review of Economics and Statistics, 95(3), 983-1001. 17

Board of Governors of the Federal Reserve System (US). 2016. Delinquency Rate on Single-Family Residential Mortgages, Booked in Domestic Offices, All Commercial Banks [DRSFRMACBS]. retrieved from FRED, Federal Reserve Bank of St. Louis, https://fred.stlouisfed.org/series/DRSFRMACBS. Accessed: August 18, 2016. 28 
Brueckner, Jan K, Calem, Paul S, \& Nakamura, Leonard I. 2012. Subprime mortgages and the housing bubble. Journal of Urban Economics, 71(2), 230-243. 20

Brueckner, Jan K, Calem, Paul S, \& Nakamura, Leonard I. 2016. House-Price Expectations, Alternative Mortgage Products, and Default. Journal of Money, Credit and Banking, 48(1), 81-112. 4

Campbell, J. Y. 2013. Mortgage Market Design. Review of Finance, 17(1), 1-33. 9, $11,13,14,27$

Cardarelli, Roberto, Igan, Deniz, \& Rebucci, Alessandro. 2008. The changing housing cycle and the implications for monetary policy. World Economic Outlook: Housing and the Business Cycle, 19. 52

Case, Karl E., Shiller, Robert J., \& Thompson, Anne. 2012. What have they been thinking? Home buyer behavior in hot and cold markets. Tech. rept. National Bureau of Economic Research. 20

Catte, Pietro, Girouard, Nathalie, Price, Robert WR, \& Andr, Christophe. 2004. Housing Markets, Wealth and the Business Cycle. 52

Cocco, Joao F. 2013. Evidence on the benefits of alternative mortgage products. The Journal of Finance, 68(4), 1663-1690. 1

Crawford, Allan, Meh, Césaire, \& Zhou, Jie. 2013. The Residential Mortgage Market in Canada: a Primer. Financial System Review, 3, 53. 13

DellAriccia, Giovanni, Igan, Deniz, \& Laeven, Luc UC. 2012. Credit booms and lending standards: Evidence from the subprime mortgage market. Journal of Money, Credit and Banking, 44(2-3), 367-384. 20

ECB. 2003. Structural Factors in the EU Housing Markets. 13, 52

Favara, Giovanni, \& Imbs, Jean. 2015. Credit supply and the price of housing. The American Economic Review, 105(3), 958-992. 4

Ferreira, Fernando, \& Gyourko, Joseph. 2012. Heterogeneity in Neighborhood-Level Price Growth in the United States, 1993 2009. The American Economic Review, 134-140. 2

Ferreira, Fernando, \& Gyourko, Joseph. 2015. A New Look at the US Foreclosure Crisis: Panel Data Evidence of Prime and Subprime Borrowers from 1997 to 2012. 4

Garmaise, Mark J. 2013. The attractions and perils of flexible mortgage lending. Review of Financial Studies, 26(10), 2548-2582. 4

Gerardi, Kristopher S, Rosen, Harvey S, \& Willen, Paul S. 2010. The impact of deregulation and financial innovation on consumers: The case of the mortgage market. The Journal of Finance, 65(1), 333-360. 4

Ghent, Andra C, \& Kudlyak, Marianna. 2011. Recourse and residential mortgage default: evidence from US states. Review of Financial Studies, hhr055. 10

Glaeser, Edward L, \& Nathanson, Charles G. 2015. An extrapolative model of house price dynamics. Tech. rept. National Bureau of Economic Research. 20 
Glaeser, Edward L., Gyourko, Joseph, \& Saiz, Albert. 2008. Housing supply and housing bubbles. Journal of Urban Economics, 64(2), 198-217. 3

International Monetary Fund. 2010. IMF Country Report No. 10/378. 17

International Monetary Fund. 2011. Housing Finance and Financial Stability - Back to Basics? 10, 13

Kaplan, Greg, \& Violante, Giovanni L. 2014. A model of the consumption response to fiscal stimulus payments. Econometrica, 82(4), 1199-1239. 5

Kaplan, Greg, Violante, Giovanni L, \& Weidner, Justin. 2014. The wealthy hand-tomouth. Brookings papers on economic activity, 77-153. 1, 5, 8

Kiff, John. 2009. Canadian Residential Mortgage Markets: Boring But Effective? International Monetary Fund. 15

Krznar, Mr Ivo, \& Morsink, James. 2014. With Great Power Comes Great Responsibility: Macroprudential Tools at Work in Canada. 15

Mian, Atif, \& Sufi, Amir. 2009. The consequences of mortgage credit expansion: Evidence from the US mortgage default crisis. The Quarterly Journal of Economics, 124(4), 1449-1496. 1, 4

Mian, Atif R, \& Sufi, Amir. 2015. Fraudulent Income Overstatement on Mortgage Applications during the Credit Expansion of 2002 to 2005. Tech. rept. National Bureau of Economic Research. 29

Ministry of Economic and Business Affairs. 2007 (Jan). Nye tider p boligmarkedet. Tech. rept. 11, 27

Piskorski, Tomasz, \& Tchistyi, Alexei. 2010. Optimal mortgage design. Review of Financial Studies, 23(8), 3098-3140. 3

Politiken. 2003. Afdragsfri lan kan fornys i det uendelige. 16 September. Last accessed: 12 May 2015. 11

Politiken. 2012. Se hvor mange der har afragsfrie lan og flekslan i din kommune. 6 December. Last accessed: 7 August 2015. 20

Rangvid, Jesper, Grosen, Anders, Østrup, Finn, Møgelvang-Hansen, Peter, Jensen, Hugo Frey, Thomsen, Jens, Schütze, Peter, Galbo, Julie, Ølgaard, Christian, Frederiksen, Niels Kleis, et al. . 2013. Den finansielle krise i Danmark: Arsager, konsekvenser og laring. Tech. rept. Erhvervs-og Vækstministeriet. 28

Scanlon, Kathleen, Lunde, Jens, \& Whitehead, Christine. 2008. Mortgage product innovation in advanced economies: More choice, more risk. European Journal of Housing Policy, 8(2), 109-131. 13, 14, 52

Sinai, Todd. 2013. House Price Moments in Boom-Bust Cycles. Housing and the Financial Crisis, 19. 2

World Bank. 2016. Bank Non-Performing Loans to Gross Loans for United States [DDSI02USA156NWDB]. retrieved from FRED, Federal Reserve Bank of St. Louis; https://fred.stlouisfed.org/series/DDSI02USA156NWDB. Accessed: August 18, 2016. 28 


\section{A Tables}

Table 1: Buyers Pre-and Post Reform - Normalized

\begin{tabular}{|c|c|c|c|c|c|c|}
\hline & $\begin{array}{l}\text { (1) } \\
\text { All }\end{array}$ & $\begin{array}{l}\text { (2) } \\
\text { All }\end{array}$ & $\begin{array}{l}\text { (3) } \\
\text { All }\end{array}$ & $\begin{array}{l}\text { (4) } \\
\text { All }\end{array}$ & $\begin{array}{l}\text { (5) } \\
\text { All }\end{array}$ & $\begin{array}{l}\text { (6) } \\
\text { All }\end{array}$ \\
\hline Post Reform & $\begin{array}{c}0.0040^{* * *} \\
(0.00028)\end{array}$ & $\begin{array}{c}0.0031^{* * *} \\
(0.00034)\end{array}$ & $\begin{array}{c}0.0031^{* * *} \\
(0.00033)\end{array}$ & $\begin{array}{c}0.0027^{* * *} \\
(0.00029)\end{array}$ & $\begin{array}{c}0.0039^{* * *} \\
(0.00028)\end{array}$ & \\
\hline Post Reform X Boom & & $\begin{array}{c}0.0025^{* * *} \\
(0.00047)\end{array}$ & & & & \\
\hline Post Reform X Housing Supply & & & $\begin{array}{c}0.0065 * * * \\
(0.00065)\end{array}$ & & & \\
\hline Post Reform X Income Growth ${ }_{t}$, Normalized & & & & $\begin{array}{l}0.0010^{* * *} \\
(0.00005)\end{array}$ & & \\
\hline Post Reform X Hand-to-Mouth $=1$ X Income Growth ${ }_{t+1}$, Normalized & & & & & & $\begin{array}{c}0.0000 \\
(0.00004)\end{array}$ \\
\hline Constant & $\begin{array}{l}-0.1654^{* * *} \\
(0.00380)\end{array}$ & $\begin{array}{l}-0.1638^{* * *} \\
(0.00387)\end{array}$ & $\begin{array}{l}-0.1723^{* * *} \\
(0.00390)\end{array}$ & $\begin{array}{l}-0.1579^{* * *} \\
(0.00382)\end{array}$ & $\begin{array}{l}-0.1665^{* * *} \\
(0.00381)\end{array}$ & $\begin{array}{l}-0.1643^{* * *} \\
(0.00378)\end{array}$ \\
\hline Observations & $3,792,805$ & $3,792,805$ & $3,792,805$ & $3,792,805$ & $3,792,805$ & $3,792,805$ \\
\hline
\end{tabular}

Notes: This table reports the OLS estimation of the probability of buying using data on the full population of Danish households in year 2002 and 2004. All regressions include municipality dummies and the following control variables. Household-level controls: The log difference between disposable income in year $t$ and $t-1$ (Income Growth $t)$, and year $t+1$ and $t($ Income Growth $t+1)$, ; lagged values for mortgage to income and interest payment to income; log income, changes in family size, age, age squared, education level, unemployed, housing tenure, housing tenure squared, and a dummy for owner. Municipality-level controls include (1) new households in the municipality, the share of poor hand-to-mouth, and wealthy hand to mouth; (2) year-over year change in the unemployment rate, mortgage rate, average disposable income, average buyer income, and (3) the lagged annual house price change. All variables with the year-over-year change are normalized by the median income growth in year $t$ to account for business-cycle effects. Robust standard errors in parenthesis. 
Table 2: Regression of Interest Only Loans on Pre-Treatment House Price Growth

\begin{tabular}{|c|c|c|c|}
\hline & \multicolumn{3}{|c|}{ IO Loan Penetration } \\
\hline & (1) & $(2)$ & (3) \\
\hline Pre-Treatment House Price Growth & $\begin{array}{c}0.15^{* *} \\
(0.03)\end{array}$ & & $\begin{array}{l}0.099^{* * *} \\
(0.03)\end{array}$ \\
\hline Buyer Income Growth ${ }_{t+2}$ & & $\begin{array}{c}1.22^{\text {** }} \\
(0.20)\end{array}$ & $\begin{array}{c}* 0.92^{* * *} \\
(0.20)\end{array}$ \\
\hline Constant & $\begin{array}{c}0.48^{* *} \\
(0.01)\end{array}$ & $\begin{array}{c}* 0.45^{* *} \\
(0.01)\end{array}$ & $\begin{array}{c}* 0.44^{* * *} \\
(0.01)\end{array}$ \\
\hline $\mathrm{N}$ & 93 & 93 & 93 \\
\hline
\end{tabular}

Notes: Dependent variable is the number of interest-only mortgages as a percentage of all mortgages for each municipality. Pre-Boom House Price Growth is the percentage increase in house prices from 1998Q1 to 2003Q3. Buyer Income Growth G $_{t+2}$ is the log difference in disposable income between 2004 and 2006. 
Table 3: Synthetic Control Weights

\begin{tabular}{|c|c|}
\hline Treated & Synthetic Control Weights \\
\hline \multicolumn{2}{|c|}{ Panel 1: International House Prices } \\
\hline Denmark & Finland: 1.00 \\
\hline \multicolumn{2}{|r|}{ Panel 2: City-Level House Prices } \\
\hline CopenhagenCity & OttawaGatineau: 1.00 \\
\hline CopenhagenSurroundings & OttawaGatineau: 0.86 ; Toronto: 0.14 \\
\hline EasternJutland & Vancouver: 0.46; Toronto: 0.32; Hamilton: 0.22 \\
\hline EasternZealand & OttawaGatineau: 0.74; Hamilton: 0.26 \\
\hline Fyn & Vancouver: 0.55 ; Hamilton: 0.45 \\
\hline NorthernJutland & Toronto: 0.67 ; Vancouver: 0.33 \\
\hline NorthernZealand & OttawaGatineau: 0.93 ; Toronto: 0.07 \\
\hline SouthernJutland & Hamilton: 0.49 ; Vancouver: 0.39 ; Toronto: 0.12 \\
\hline WesternJutland & Vancouver: 0.52 ; Toronto: 0.48 \\
\hline WestSouthZealand & OttawaGatineau: 0.83 ; Toronto: 0.17 \\
\hline \multicolumn{2}{|c|}{ Panel 3: Helsinki City-Level House Prices } \\
\hline Helsinki & Halifax: 0.57 ; OttawaGatineau: 0.41 ; Hamilton: 0.01 \\
\hline
\end{tabular}

Notes: Synthetic Control unit weights. Only regions with positive weight are listed. 
Table 4: Average Pre-treatment Predictor Values

\begin{tabular}{|c|c|c|c|}
\hline \multicolumn{4}{|c|}{ Panel 1: Denmark; House Prices } \\
\hline & Treated & Synthetic & Sample Mean \\
\hline Dur Cons per Capita & 382.48 & 235.71 & 305.80 \\
\hline GARCH Volatility & 0.84 & 0.92 & 0.96 \\
\hline GDP Per Capita & 41505.31 & 30056.68 & 26609.96 \\
\hline House Price Index & 117.64 & 116.11 & 115.22 \\
\hline Pre-treatment HPI Growth & 31.65 & 29.88 & 37.73 \\
\hline Private Credit Flows & 118.37 & 125.07 & 132.18 \\
\hline \multicolumn{4}{|c|}{ Panel 2: CopenhagenCity; House Prices } \\
\hline & Treated & Synthetic & Sample Mean \\
\hline GARCH Volatility & 0.64 & 0.40 & 0.44 \\
\hline House Price Index & 119.73 & 113.83 & 109.54 \\
\hline Median Income 2001 Std & -0.45 & 1.77 & 0.15 \\
\hline Pop 2001 Std & 0.68 & 0.17 & 0.67 \\
\hline Pre-treatment HPI Growth & 37.05 & 32.89 & 23.33 \\
\hline Unemp 2001 Std & 1.76 & -0.55 & -0.12 \\
\hline \multicolumn{4}{|c|}{ Panel 3: CopenhagenSurroundings; House Prices } \\
\hline & Treated & Synthetic & Sample Mean \\
\hline GARCH Volatility & 0.32 & 0.37 & 0.44 \\
\hline House Price Index & 115.48 & 113.56 & 109.54 \\
\hline Median Income 2001 Std & 0.96 & 1.78 & 0.15 \\
\hline Pop 2001 Std & 0.20 & 0.62 & 0.67 \\
\hline Pre-treatment HPI Growth & 29.75 & 31.78 & 23.33 \\
\hline Unemp 2001 Std & -0.42 & -0.53 & -0.12 \\
\hline
\end{tabular}

Notes: Average pre-treatment predictor values for selected Samples. 
Table 5: Synthetic Control-Estimated Effects of IO Loans

\begin{tabular}{|c|c|c|c|c|c|}
\hline \multirow[b]{2}{*}{ Treated Unit } & \multirow[b]{2}{*}{ RMSFE } & \multicolumn{2}{|c|}{ Gap } & \multicolumn{2}{|c|}{ Gap/Path } \\
\hline & & Boom & Bust & Boom & $\overline{\text { Bust }}$ \\
\hline \multicolumn{6}{|c|}{ Panel 1: International House Prices } \\
\hline Denmark & 15.98 & $35.80^{*}$ & $-23.36^{*}$ & 0.62 & 1.60 \\
\hline \multicolumn{6}{|c|}{ Panel 2: City-Level House Prices } \\
\hline CopenhagenCity & 42.14 & $52.32^{*}$ & $-30.20^{*}$ & 0.77 & 2.98 \\
\hline CopenhagenSurroundings & 7.53 & $40.32^{*}$ & $-32.09 *$ & 0.72 & 2.54 \\
\hline EasternJutland & 2.98 & 8.03 & $-15.35^{*}$ & 0.19 & -45.32 \\
\hline EasternZealand & 7.08 & $34.31^{*}$ & $-31.07^{*}$ & 0.66 & 2.36 \\
\hline Fyn & 2.41 & -2.82 & $-13.58^{*}$ & -0.08 & -9.73 \\
\hline NorthernJutland & 3.19 & -1.85 & $-5.89^{*}$ & -0.07 & -0.57 \\
\hline NorthernZealand & 9.72 & $36.53^{*}$ & $-38.43^{*}$ & 0.70 & 2.06 \\
\hline SouthernJutland & 3.12 & -4.54 & -4.58 & -0.16 & -0.46 \\
\hline WesternJutland & 4.67 & -9.38 & -0.65 & -0.36 & -0.04 \\
\hline WestSouthZealand & 7.37 & $19.89^{*}$ & $-26.05^{*}$ & 0.56 & 3.88 \\
\hline \multicolumn{6}{|c|}{ Panel 3: Helsinki City-Level House Prices } \\
\hline Helsinki & 27.19 & 3.68 & NA & 0.15 & $\overline{\mathrm{NA}}$ \\
\hline
\end{tabular}

Notes: The estimated causal impact of the introduction of IO loans using the SCM. The first three columns show the sample used in the estimation, the treated unit, and the outcome variable. The fourth column holds the RMSFE from the SCM estimation. The right two panels show the estimated casual effects of the IO policy intervention. When house prices are the outcome variable, Gap is the gap in the house price growth between the treated unit and its Synthetic Control and Gap/Path is Gap divided by total house price growth for the treated unit. The results are computed for the boom period (2003Q4 - 2006Q4) and the bust period (2007Q1 - 2010Q1). For durable consumption, the results are in Euros per capita and accumulated over the boom and bust periods, respectively. To calculate the cumulative decline of the policy during the bust when durable consumption is the outcome variable, we set durable consumption to zero in 2007Q1. For the boom (bust) period, an asterisk indicates that the effect for the treated unit is larger (smaller) than all estimated placebo effects. 
Table 6: Summary of Results-Gap in House Prices Across Boom and Bust Periods

\begin{tabular}{lcccccc}
\hline & \multicolumn{2}{c}{ Boom } & & \multicolumn{2}{c}{ Bust } \\
\cline { 2 - 3 } \cline { 5 - 6 } \cline { 5 - 6 } & Estimate & Boot SE & & Estimate & Boot SE \\
\hline Mean-All & $30.27^{*}$ & 2.69 & & $-24.44^{*}$ & 1.23 \\
Median-All & $34.38^{*}$ & 4.06 & & $-26.25^{*}$ & 1.36 \\
\hline CopenhagenCity & $60.53^{*}$ & 3.15 & & $-29.37^{*}$ & 0.32 \\
CopenhagenSurroundings & $54.69^{*}$ & 5.47 & & $-29.16^{*}$ & 1.11 \\
EasternJutland & $25.33^{*}$ & 7.00 & & $-21.65^{*}$ & 3.23 \\
EasternZealand & $46.68^{*}$ & 4.33 & & $-32.57^{*}$ & 0.51 \\
Fyn & $18.79^{*}$ & 8.53 & & $-17.32^{*}$ & 3.14 \\
NorthernJutland & 7.80 & 4.12 & & $-17.12^{*}$ & 5.97 \\
NorthernZealand & $50.24^{*}$ & 5.16 & & $-37.76^{*}$ & 0.31 \\
SouthernJutland & 7.89 & 5.42 & & $-15.23^{*}$ & 2.86 \\
WesternJutland & 12.14 & 8.48 & & $-18.91^{*}$ & 3.97 \\
WestSouthZealand & $17.95^{*}$ & 2.57 & & $-25.47^{*}$ & 4.14 \\
\hline
\end{tabular}

Notes: Summary of results across all of the permutations of the data listed in table 8. In each panel, the left column holds mean gap in cumulative housing returns all permutations of the data; the corresponding bootstrapped standard error is the the right column. The results in the boom period (2003Q4-2006Q4) are in the left panel, while the right panel shows the results over the bust period (2007Q1 2010Q1). The first two rows show the mean and the median the estimated causal effects over all permutations of the data; the remaining rows show the results for specific Copenhagen Cities. An asterisk represents a bootstrapped p-value of less than 0.05 . 


\section{B Figures}

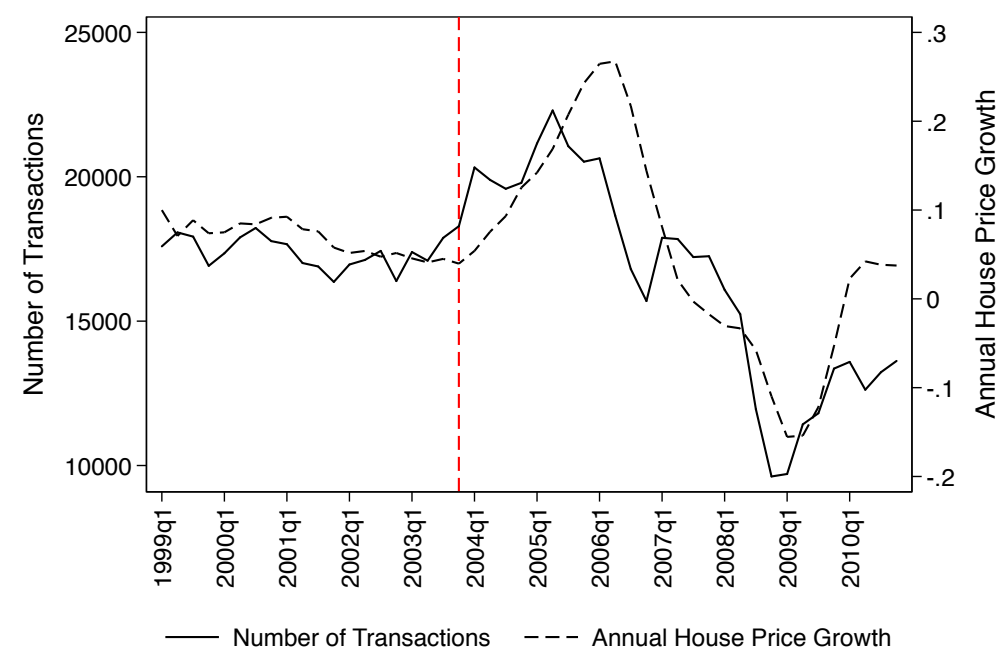

Figure 1: Number of Transactions and House Prices

Notes: Red line shows when Interest-Only mortgages were introduced in Denmark. Solid line shows the seasonally adjusted number of single-family houses and apartment transactions per quarter. Dashed line shows the year-over-year percentage change in the single-family house price index.

Source: Denmark Statistics

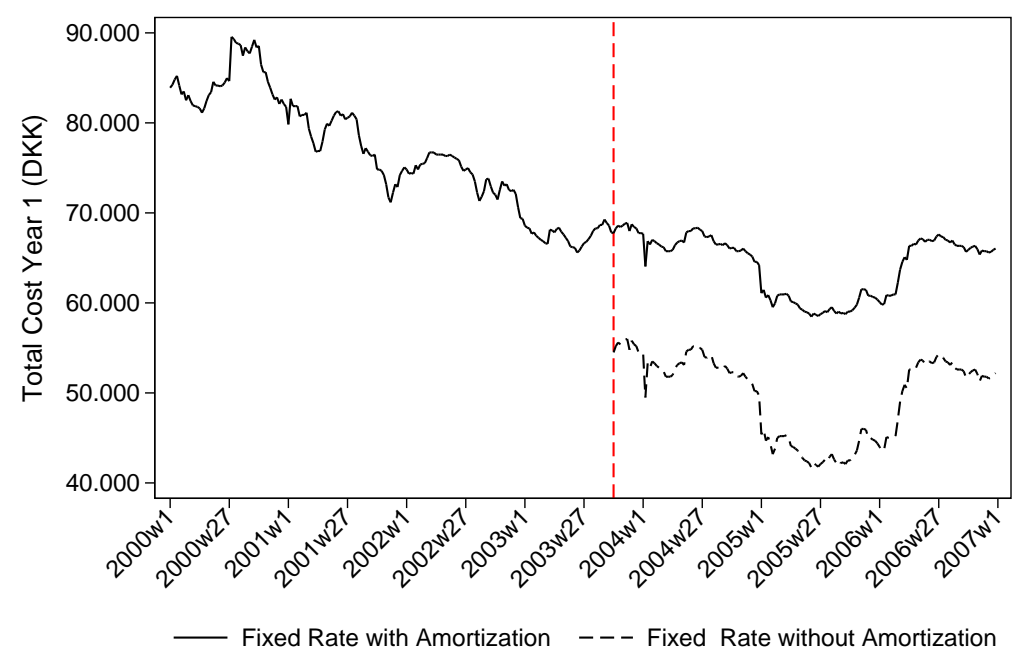

Figure 2: First Year Payments

Notes: The red vertical line indicates the introduction of interest-only mortgages. The figure plots the total annual cost for a 1 million DKK, fixed rate mortgage contract, with amortization payments (solid line) and without amortization payments (dashed line). Both lines are calculated using the long-bond rate from the Association of Danish Mortgage Banks.

Source: Association of Danish Mortgage Banks and authors' calculations 
Figure 3: Mortgage Loan Types

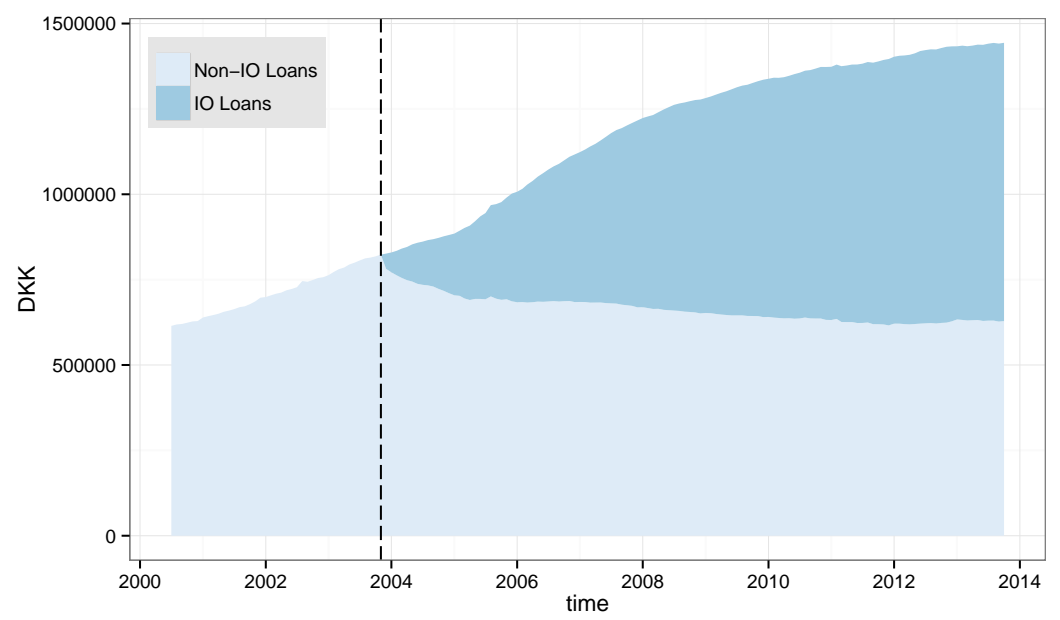

Notes: Outstanding mortgage debt by loan type. Includes loans for residential properties and vacation homes. Source: Nationalbanken

Figure 4: Interest-Only Loan Penetration in Danish Municipalities

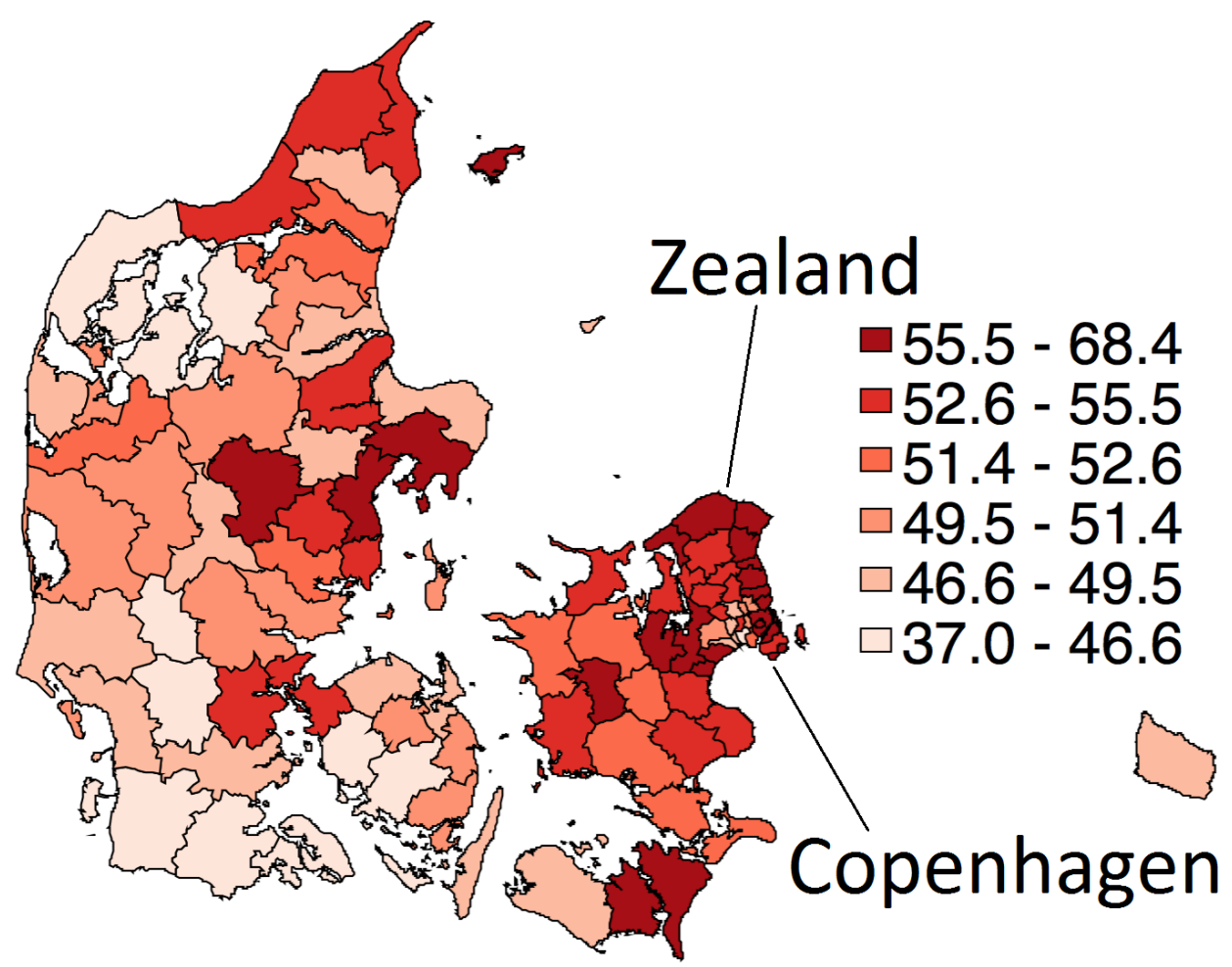


Figure 5: Interest-Only Loan Penetration, Pre-Treatment House Price Growth and Income Growth

(a) Income Growth

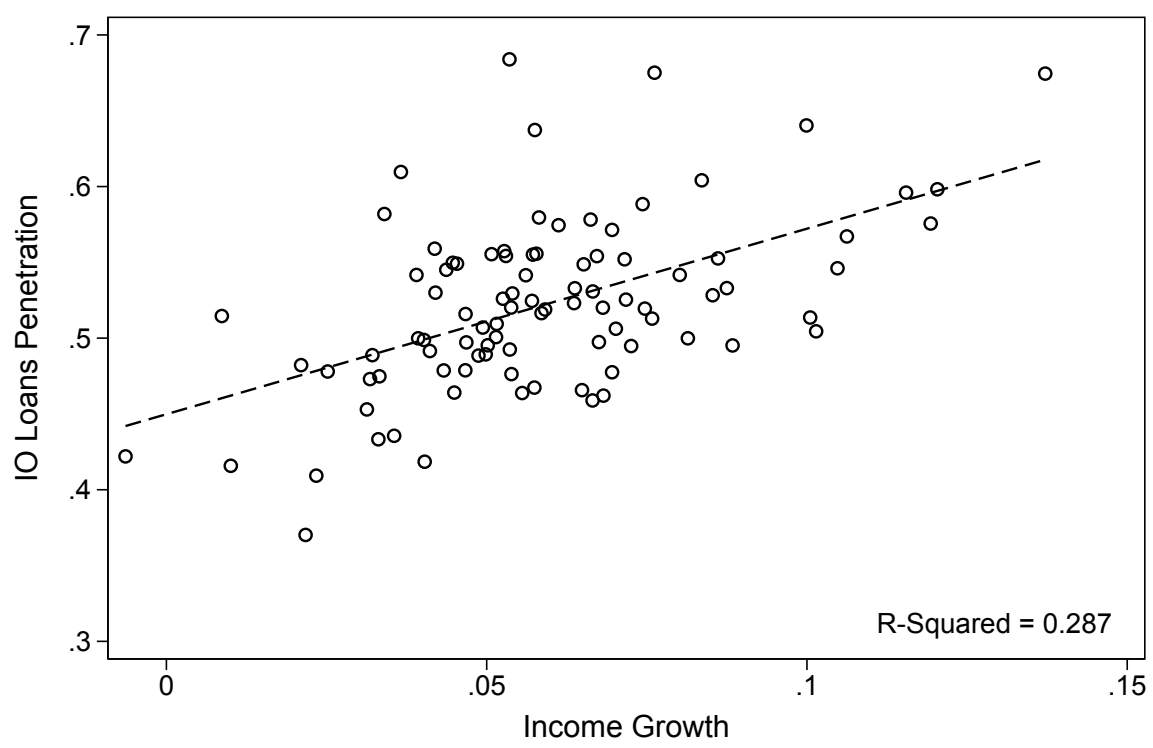

(b) Pre-Treatment House Price Growth

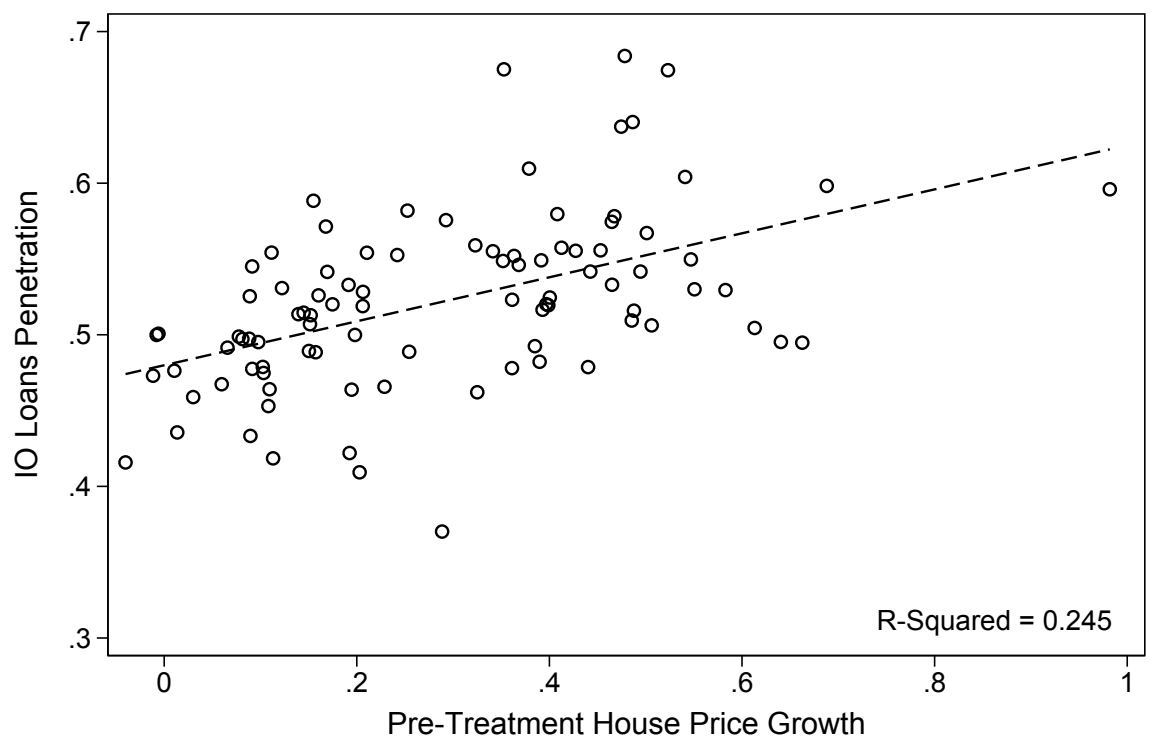

Notes: IO Loan Penetration is the percentage of Interest-only loan in each Danish municipality. Pre-Boom House Price Growth is the percentage increase in house prices from 1998Q1 to 2003Q3. Buyer Income Growth $_{t+2}$ is the log difference in disposable income between 2004 and 2006. R-squared is from a linear regression of IO loan penetration and the $\mathrm{x}$-axis variable. 

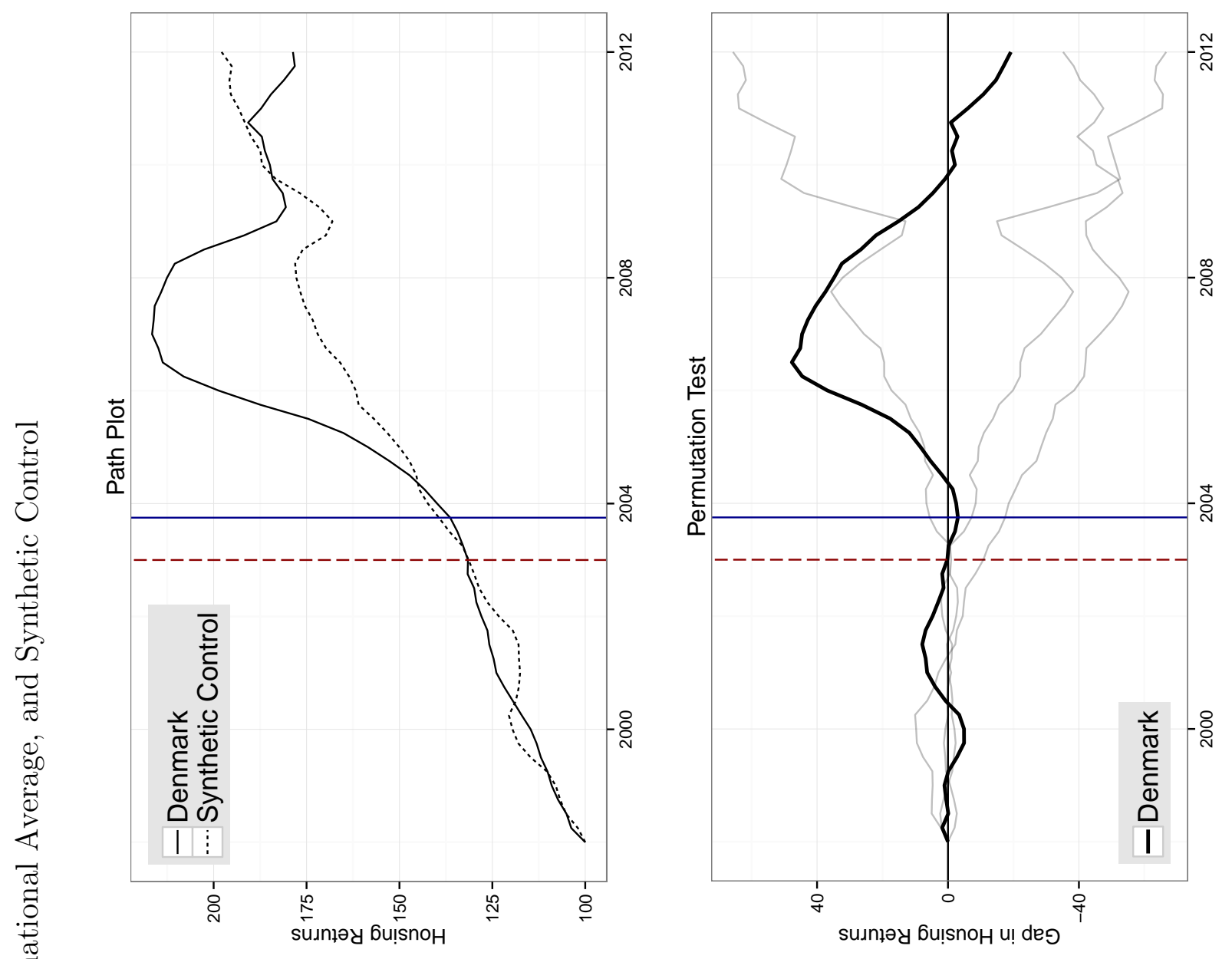

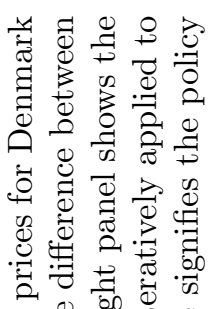

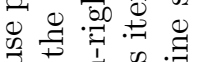

요의

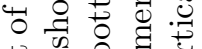

눙

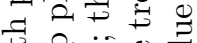

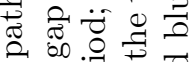

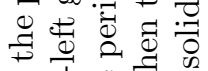

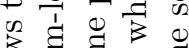

요요 की

क

고용

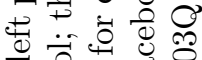

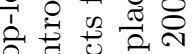

유욜

开.

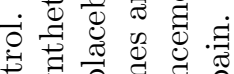

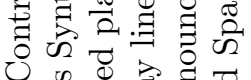

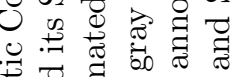

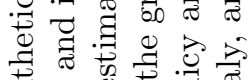

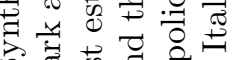

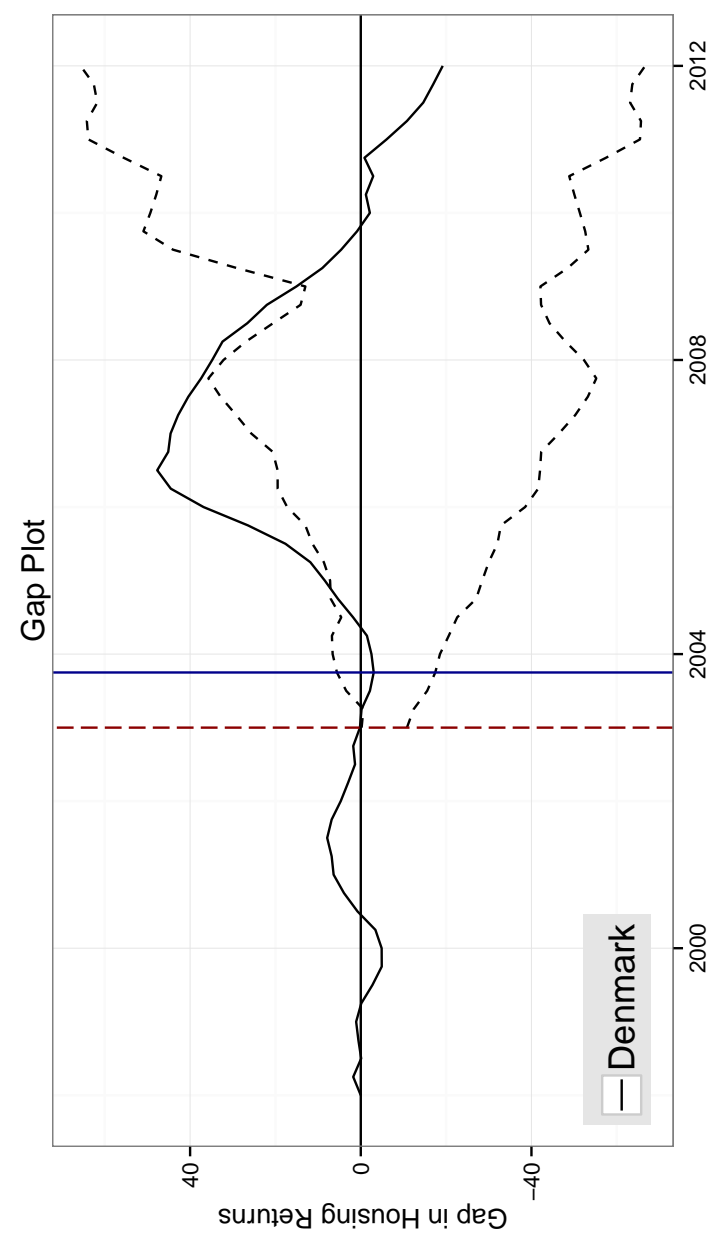

क

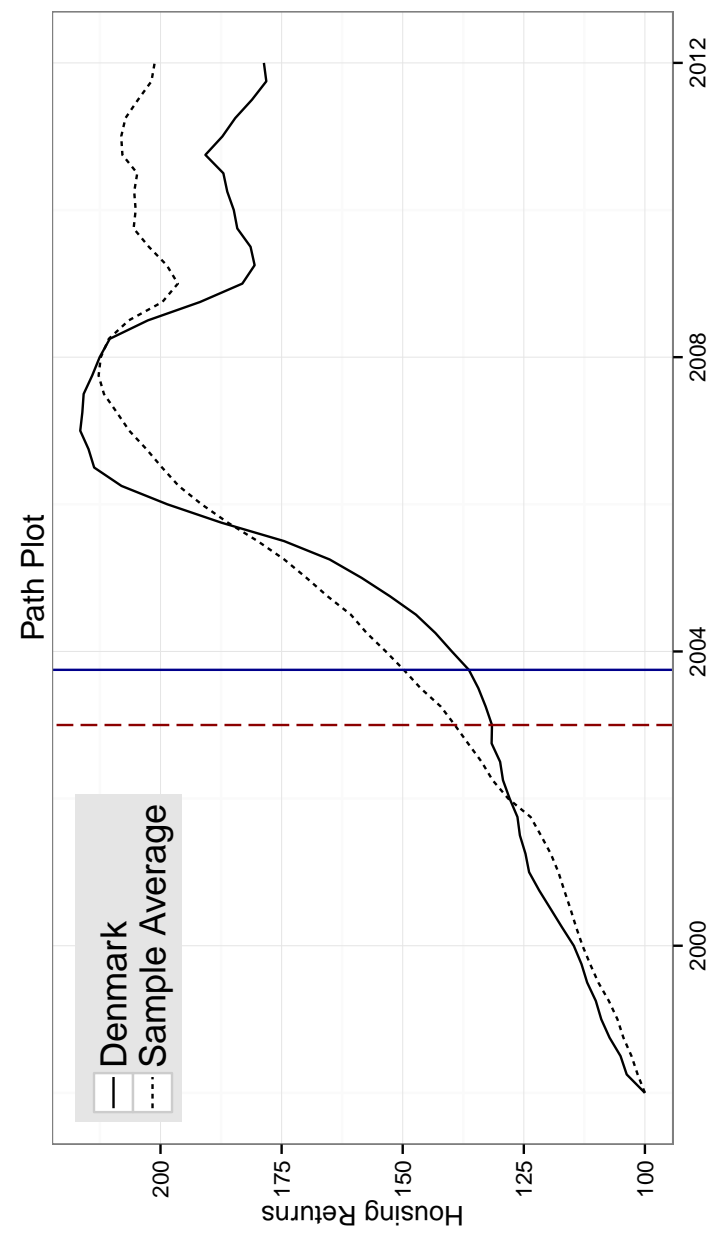

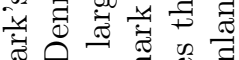

票出

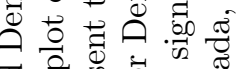

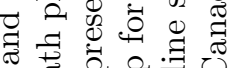

o 2000

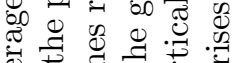

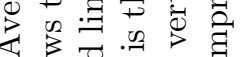

बี

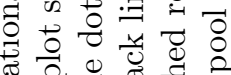

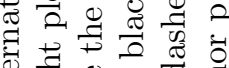

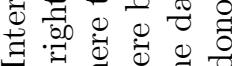

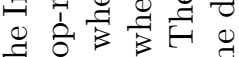

+0 范

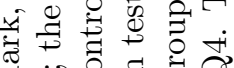

घ

踏.

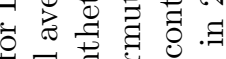

㱐密

进 की

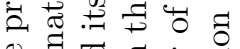

芯芯

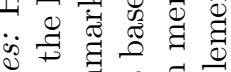

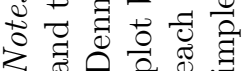



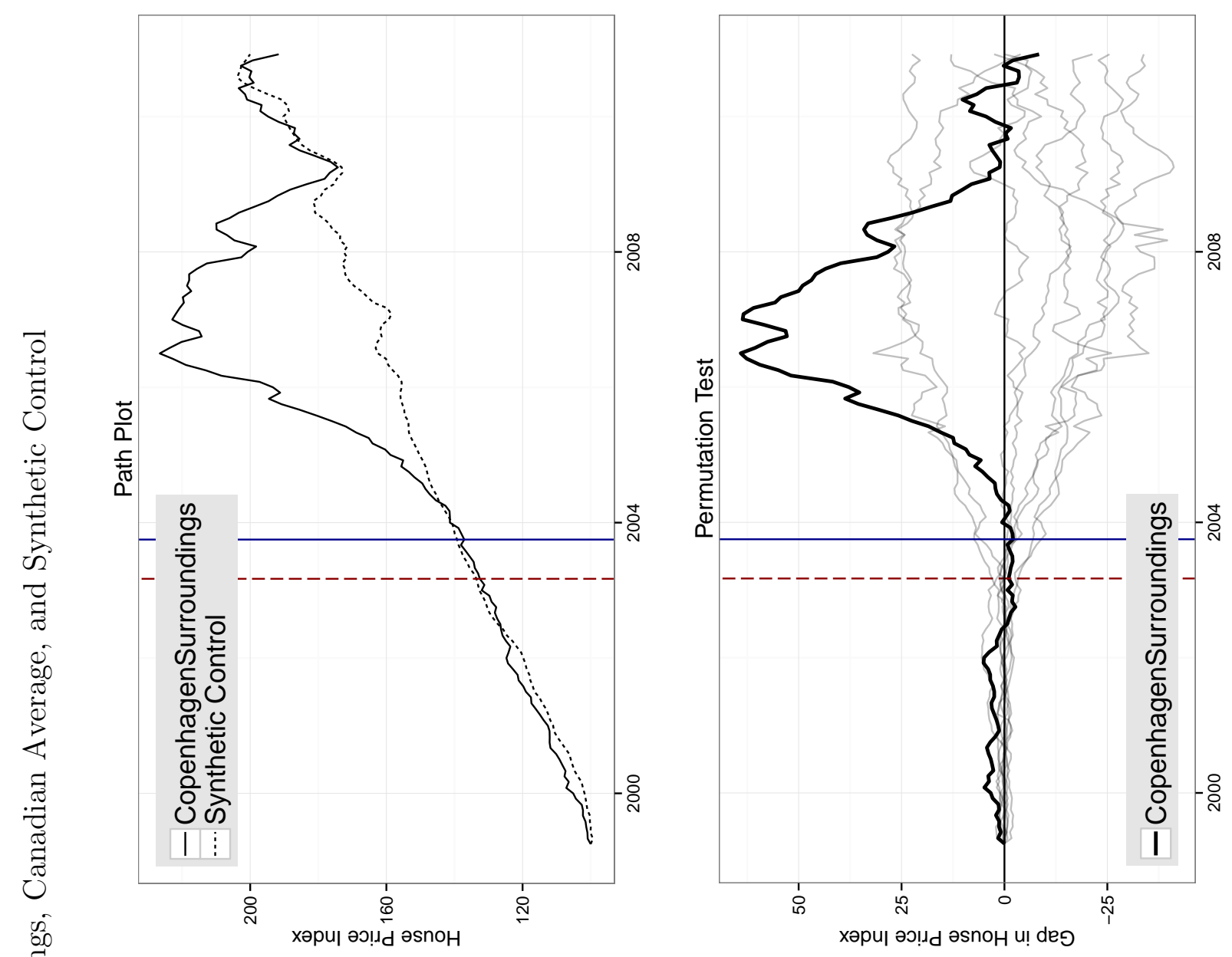

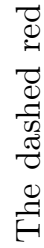

它

웡

․․․

D.

궁

.

胥

हี है

फै द्व

罂

잉

둥

\&

ธิ듀.

$\approx . \Xi$

సี

곡

吾
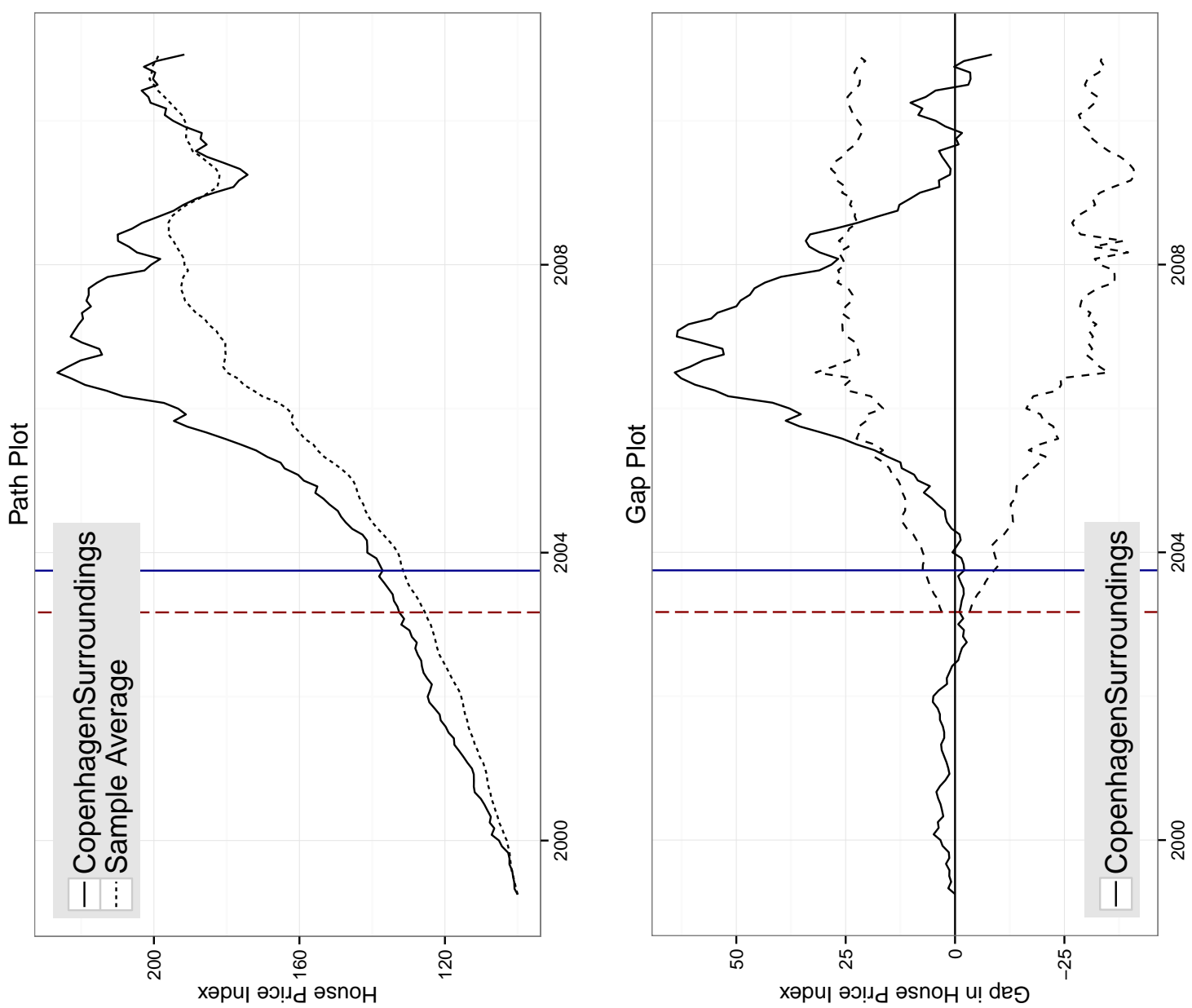

뭄

능 긍

융

จ

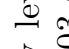

อ

总

告

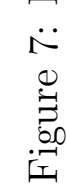


Figure 8: Mortgage Arrears and Repossessed Homes

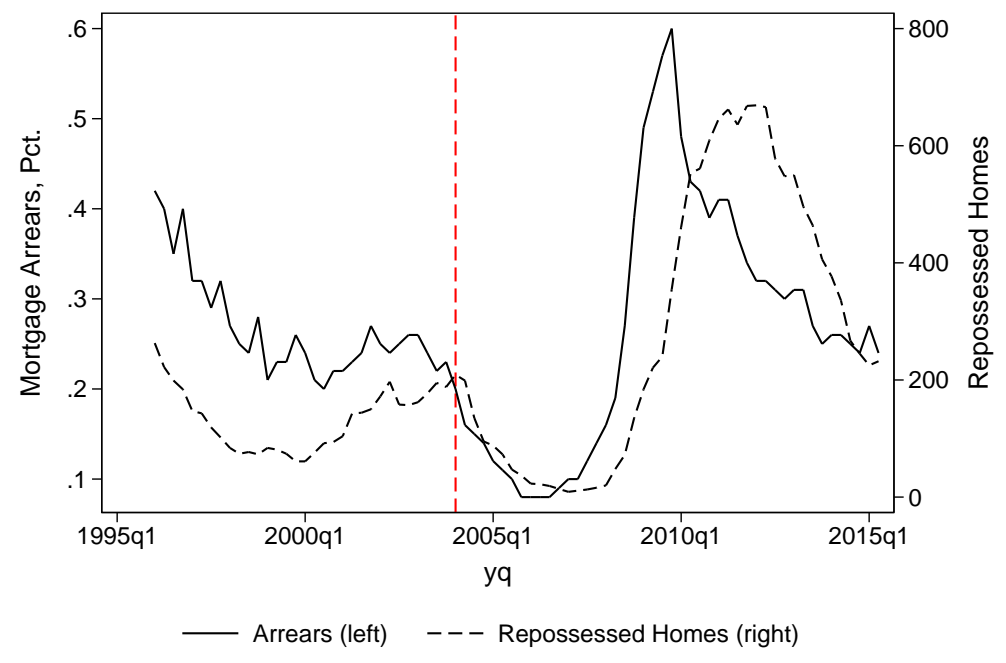

Source: Association of Danish Mortgage Banks 
Figure 9: Distribution of Income, for House-Buyers
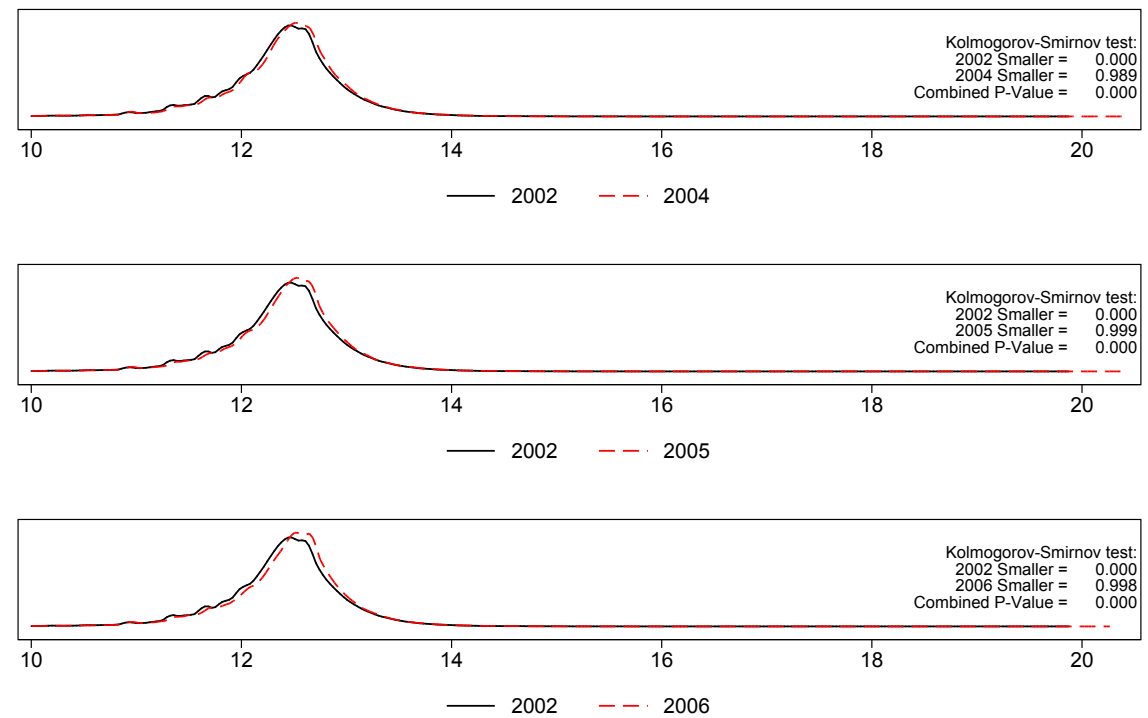

Notes: Distribution of income for households who purchased real estate in 2002 (black, solid line) and subsequent years (red, dashed line). Income is total income from labor including transfers, in logs.

Figure 10: Distribution of Financial Wealth, for House-Buyers
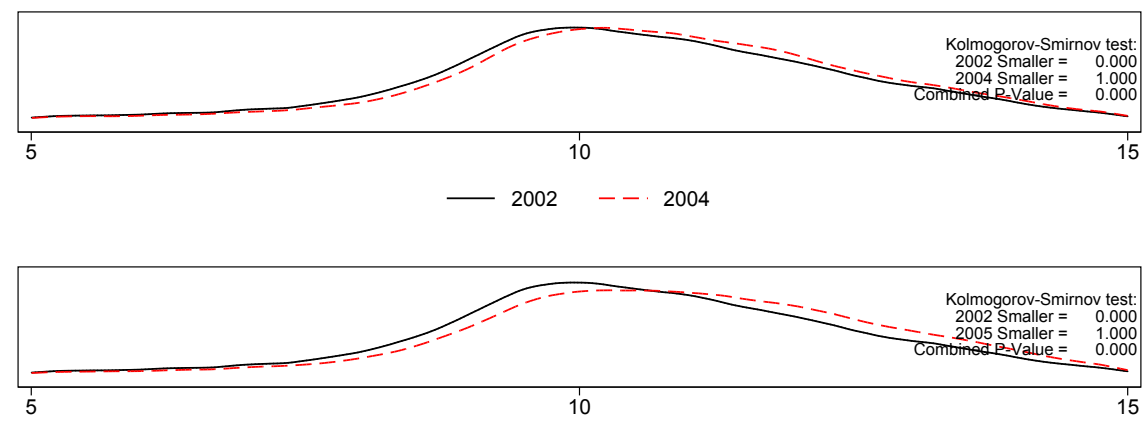

$-2002--2005$

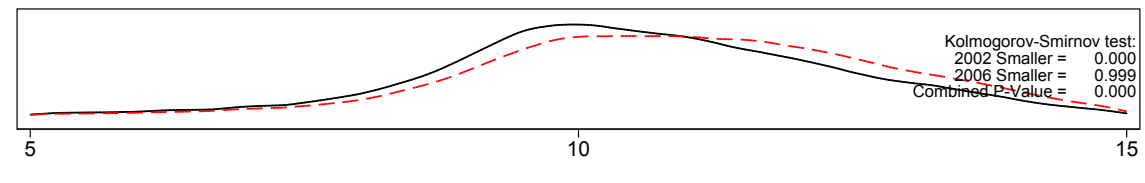

Notes: Distribution of financial wealth for households who purchased real estate in 2002 (black, solid line) and subsequent years (red, dashed line). Net wealth is the sum of stocks, bonds and cash deposits in logs. 
Figure 11: Distribution of Mortgage Payments to Income, for House-Buyers
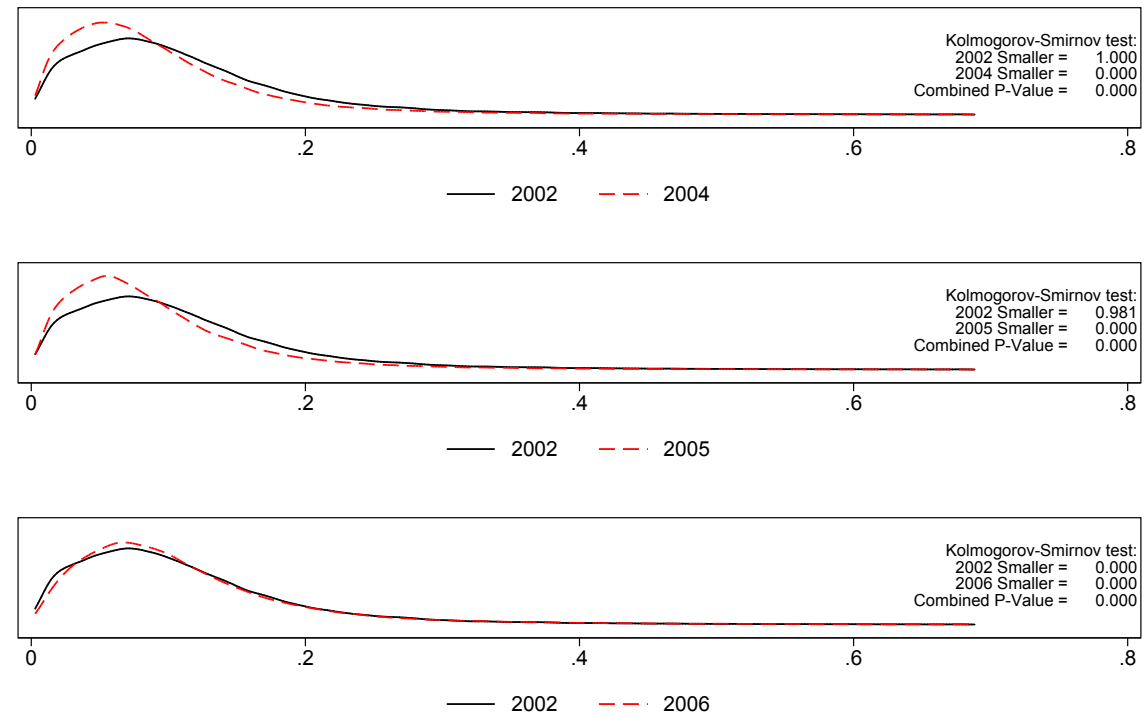

Notes: Distribution of mortgage interest payments divded by income for households who purchased real estate in 2002 (black, solid line) and subsequent years (red, dashed line).

Figure 12: Distribution of Age, for House-Buyers
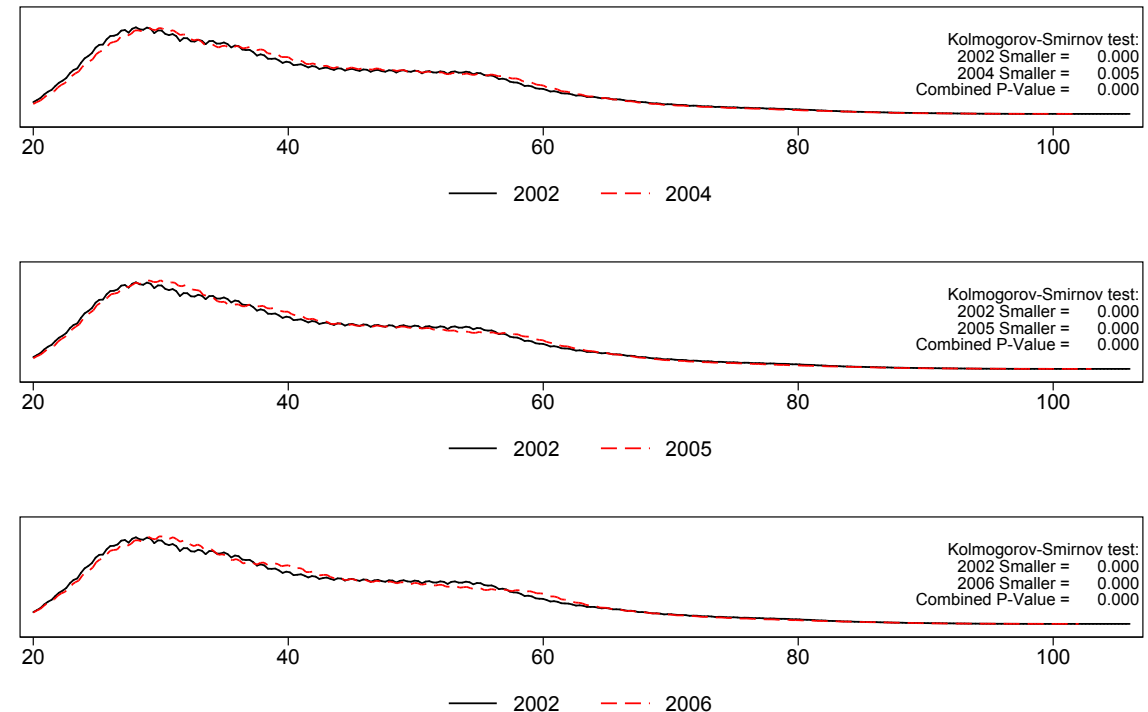

Notes: Distribution of age for households who purchased real estate in 2002 (black, solid line) and subsequent years (red, dashed line). 
Figure 13: Mortgage Debt by Income Quintile

(a) All Households

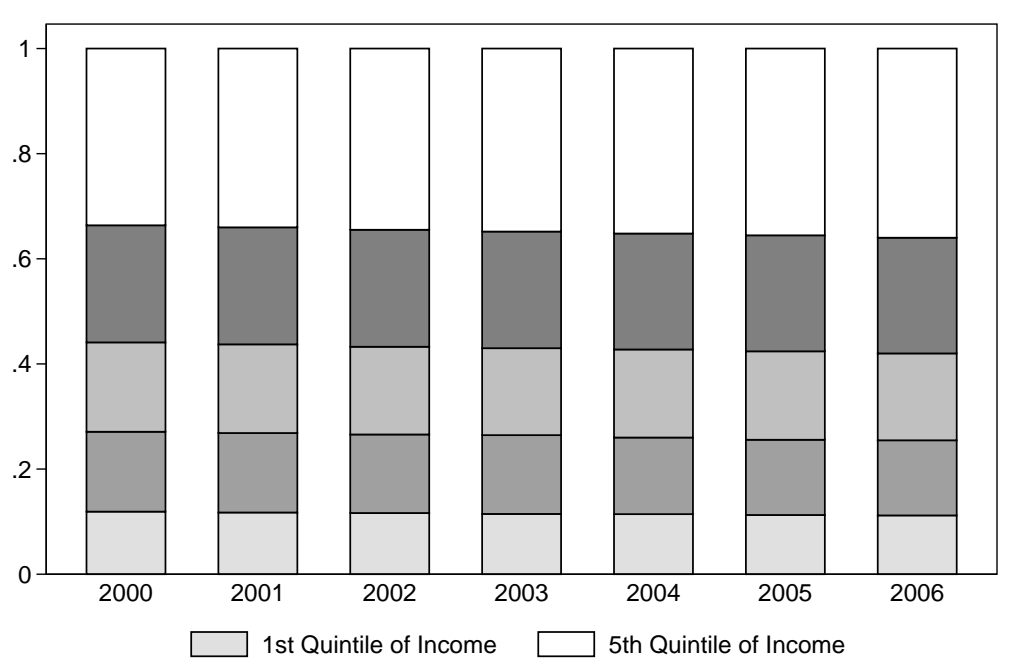

(b) Buyers

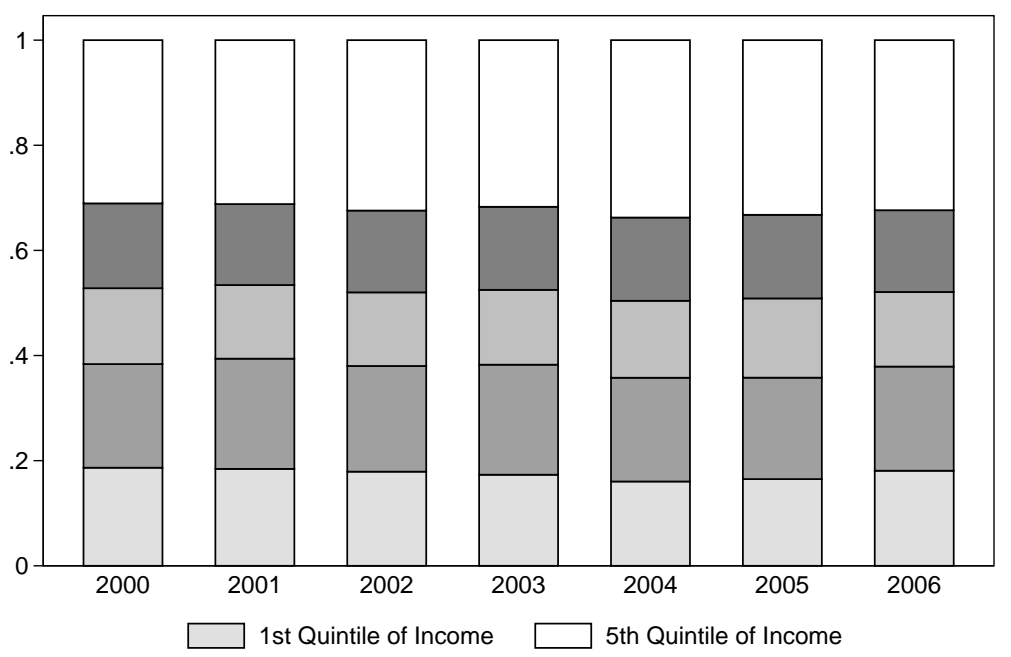

Notes: The figures show the fraction of total mortgage debt held by each income quintile. Mortgage debt is measured at end-of-year values. Panel (a) show the results all households who hold mortgage debt. Panel (b) shows the results for households who purchased housing in the given year. 
C Appendix: Data (For Online Publication) 


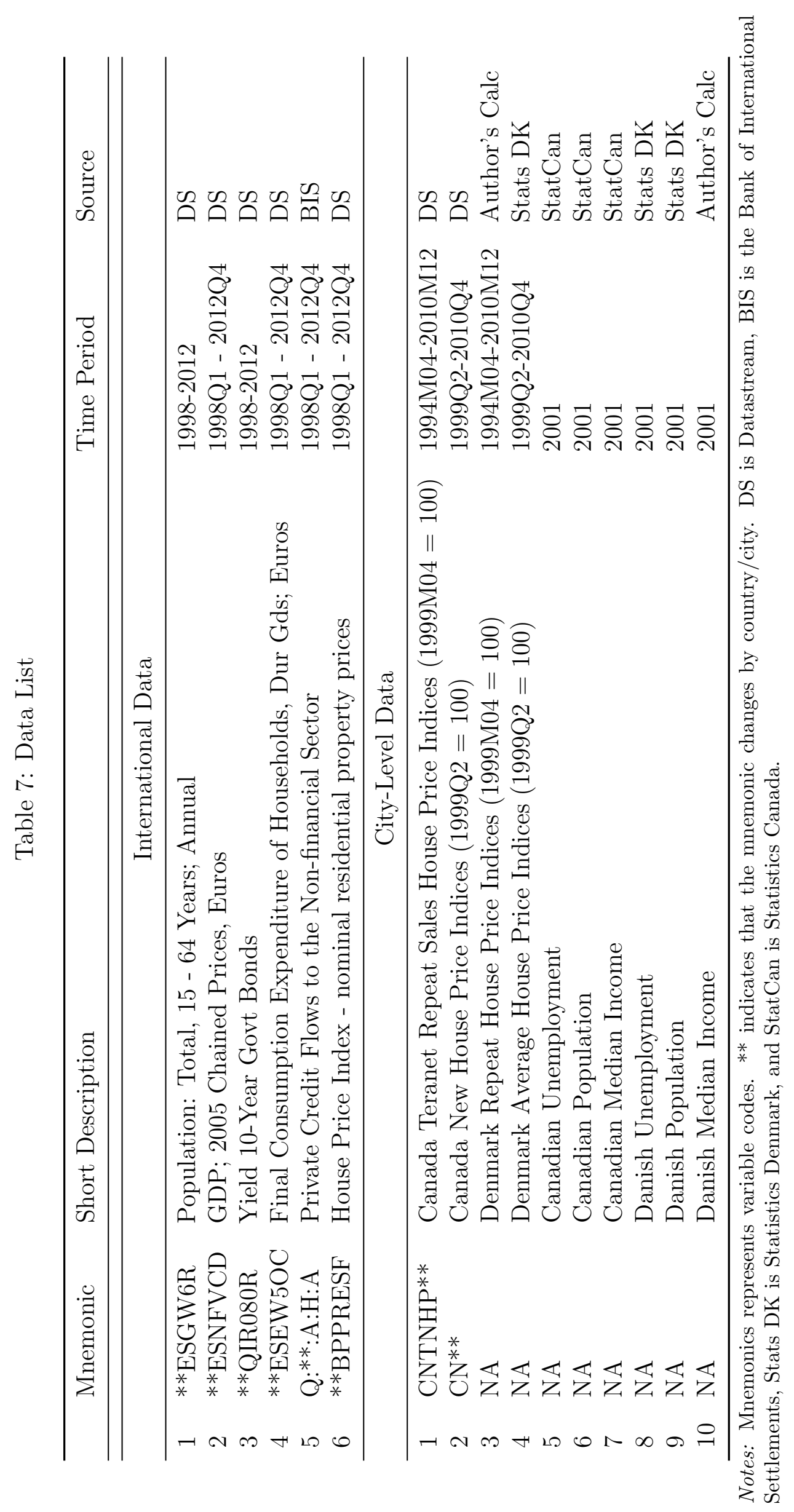




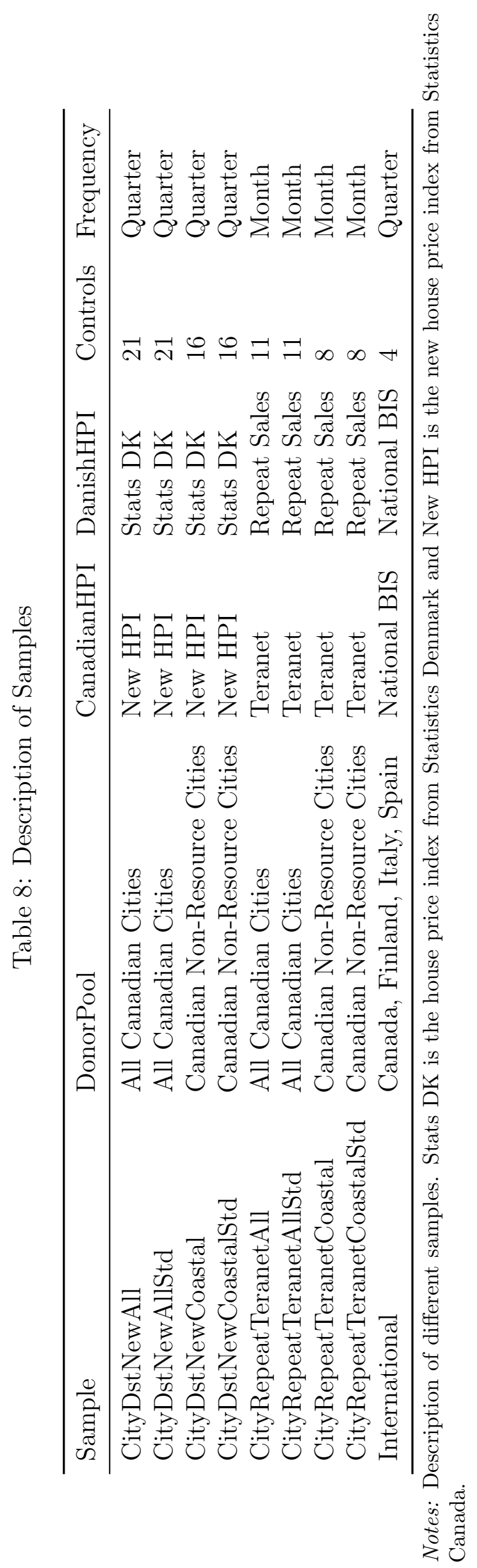




\section{Appendix: Tables (For Online Publication)}

Table 9: Mortgage Market Characteristics

\begin{tabular}{lccccc}
\hline Country & $\begin{array}{c}\text { Typical } \\
\text { Loan Term }\end{array}$ & $\begin{array}{c}\text { Mortgage } \\
\text { Loan Type }\end{array}$ & $\begin{array}{c}\text { Maximum } \\
\text { LTV Ratio }\end{array}$ & $\begin{array}{c}\text { Mortgage Debt } \\
\text { (\% of GDP) }\end{array}$ & $\begin{array}{c}\text { House Price } \\
\text { Growth }(1998-2002)\end{array}$ \\
\hline Denmark & 30 & Fixed & $80 \%$ & 74.3 & $32 \%$ \\
Finland & $15-18$ & Variable & $80 \%$ & 31.8 & $30 \%$ \\
Canada & 25 & Mixed* & $80 \%$ & 43.1 & $27 \%$ \\
Italy & 15 & Fixed & $80 \%$ & 11.4 & $28 \%$ \\
Spain & 15 & Variable & $100 \%$ & 32.3 & $66 \%$ \\
U.S. & 30 & Fixed & NA & 58.0 & $49 \%$ \\
\hline & Interest-rate & Full & Fee-free & Equity & Interest-Only \\
& Deduction & Recourse & Pre-Payment & Withdrawal & Mortgages \\
\hline Denmark & Yes & Yes & Yes & Yes & Yes \\
Finland & Yes & Yes & No & Yes & No \\
Canada & No & Yes & No & Yes & No \\
Italy & Yes & Yes & No & No & No \\
Spain & Yes & Yes & No & Limited & Yes \\
U.S. & Yes & No & Yes & Yes & Tos
\end{tabular}

Notes: We define a country as having fixed interest rates if a majority of loans have a fixed interest rate for 5 or more years. House price growth defined as the percentage increase in the BIS house price indices for all countries from 1998Q1 to 2002Q4. Mortgage debt is defined as residential mortgage debt in 2002 for all countries.

Sources: Catte et al. (2004), ECB (2003), Scanlon et al. (2008), and Cardarelli et al. (2008).

* The predominant loan type in Canada is defined as mixed, as Canadian mortgages typically have a fixed 25-year term, where the interest rate is negotiated every 5 years. 


\section{E Appendix: Figures (For Online Publication)}

Figure 14: Map of Denmark

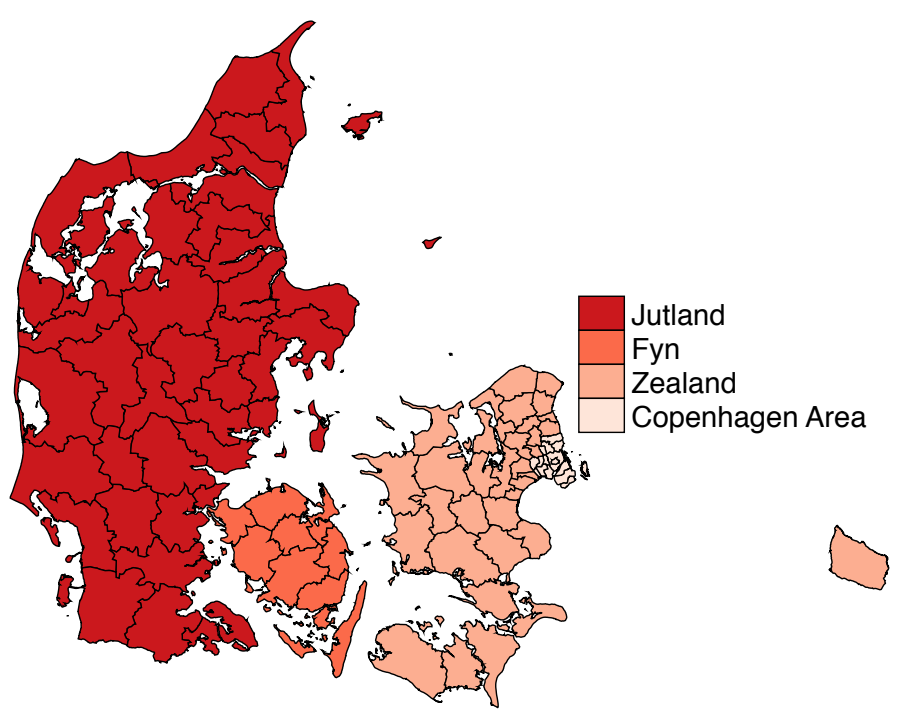




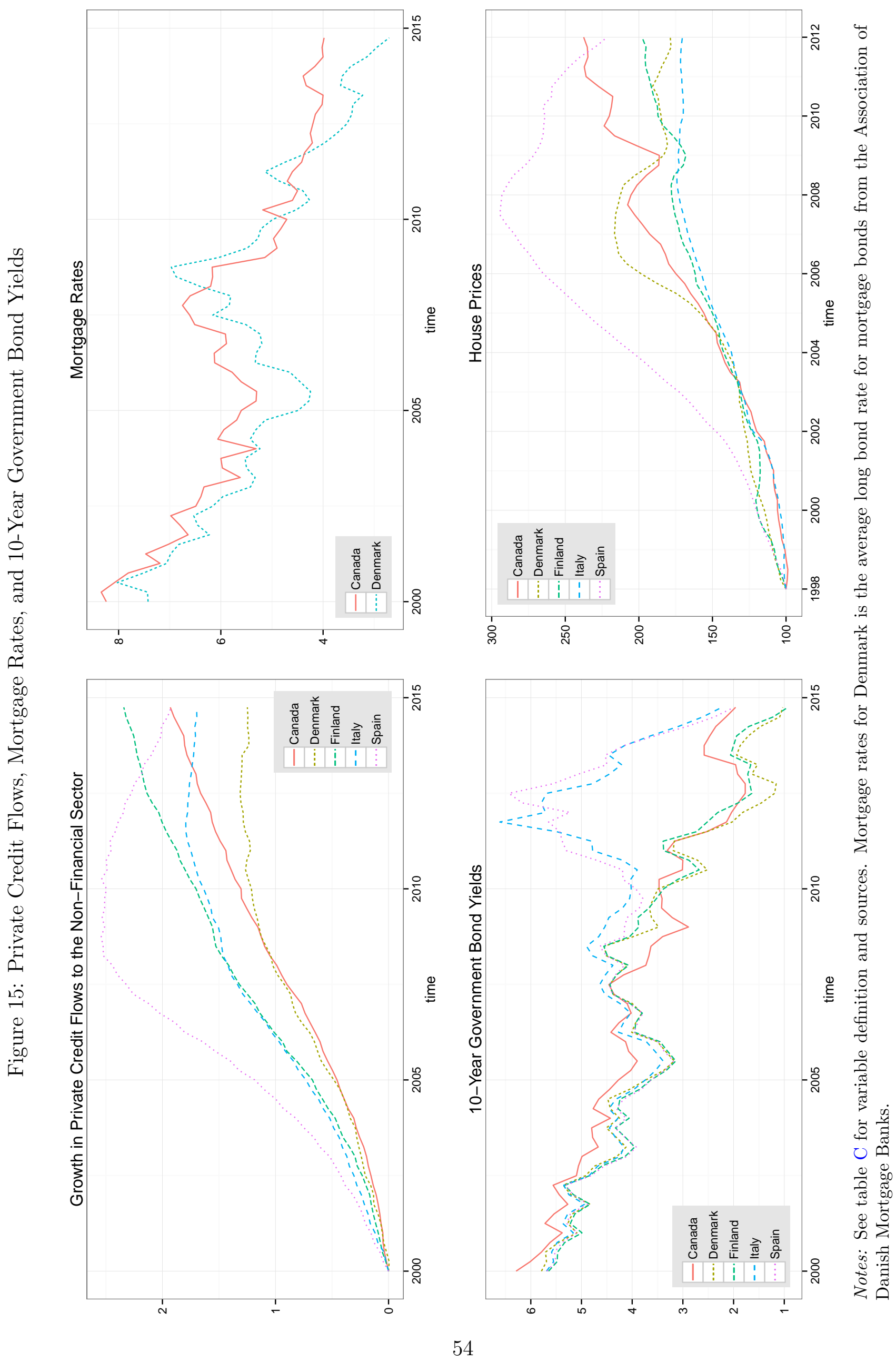


Figure 16: City-Level House Price Permutation Tests
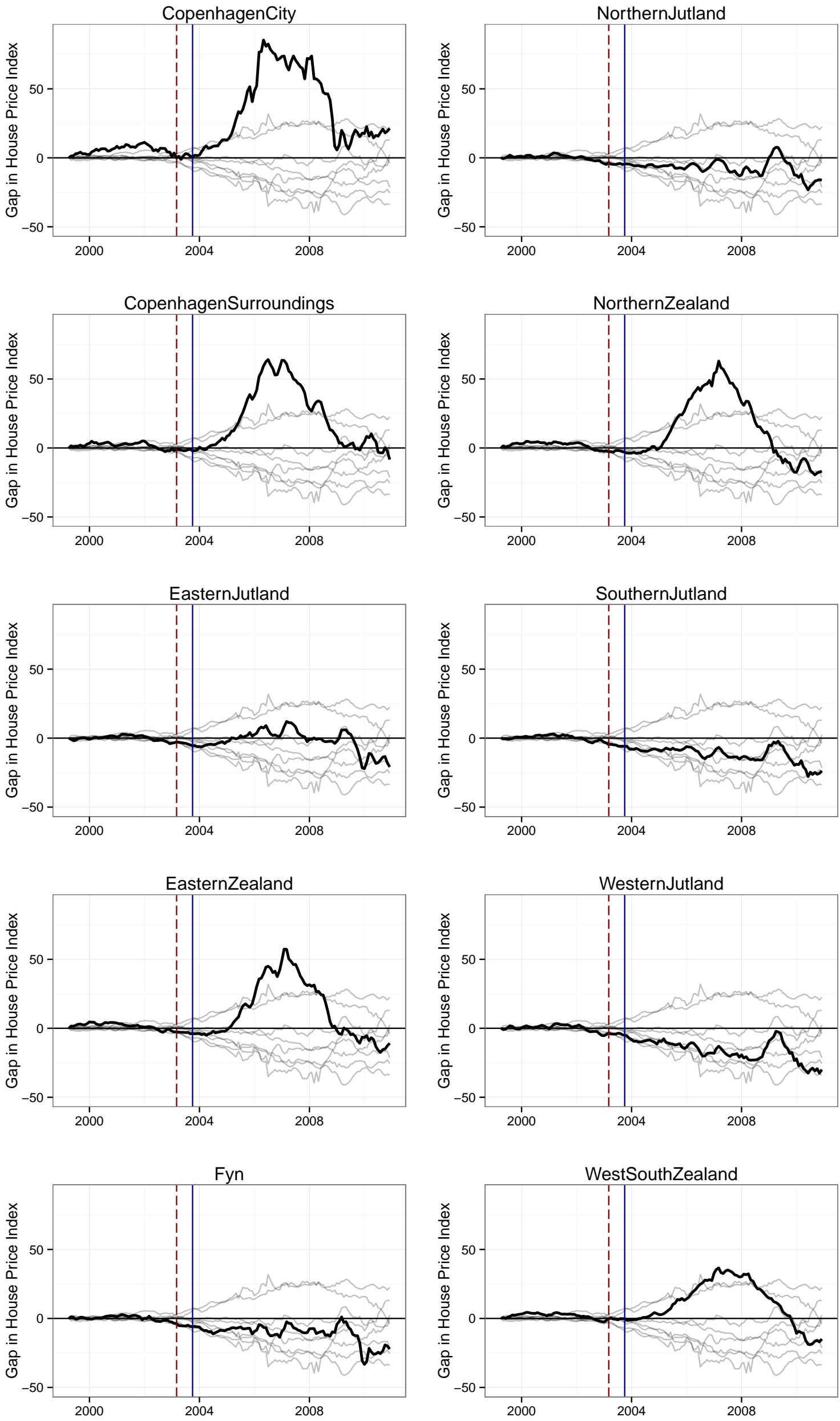

Notes: See the notes for figure 7. These plots show the permutation tests for Danish cities where the donor pool consists of Canadian non-resource cities. 

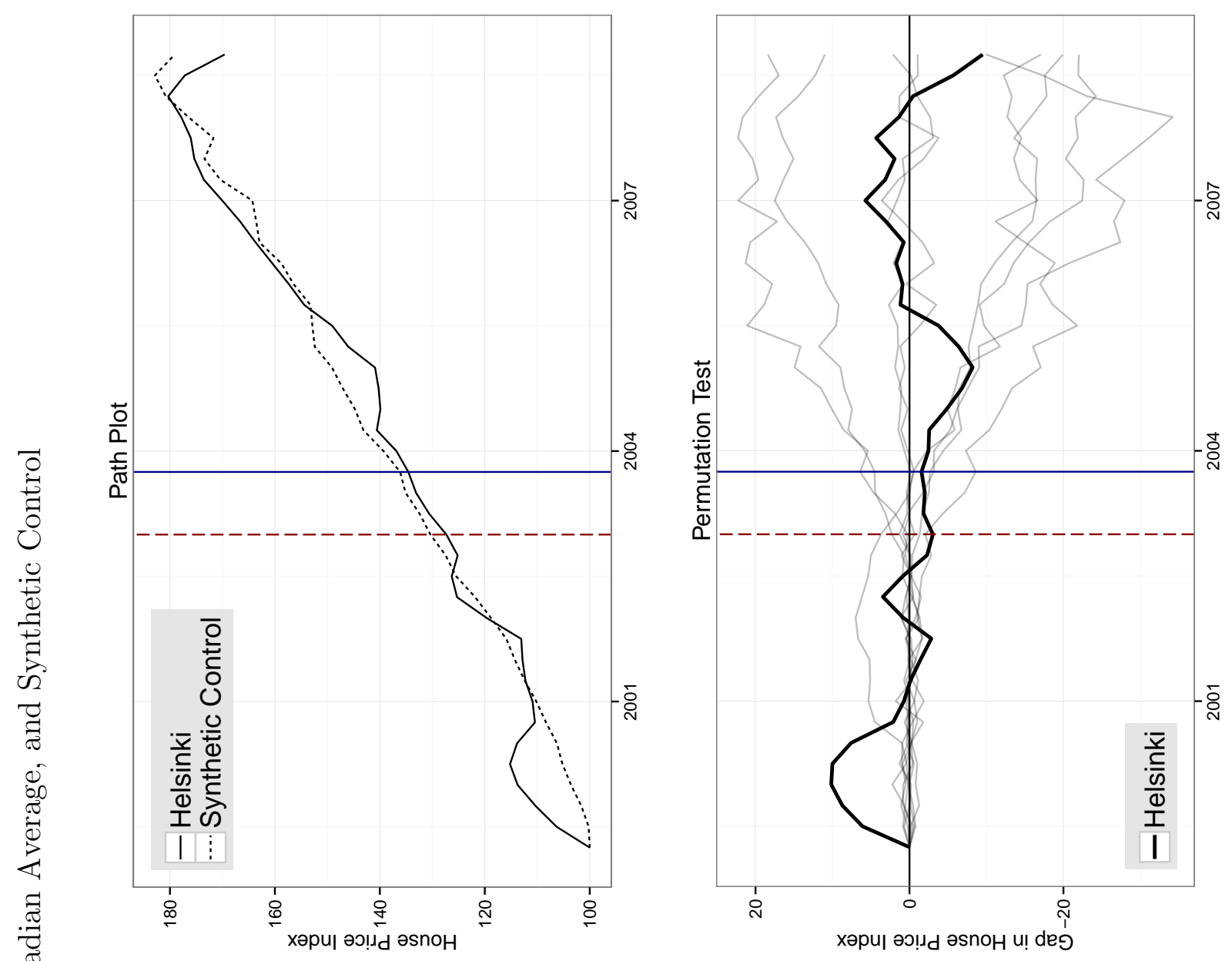

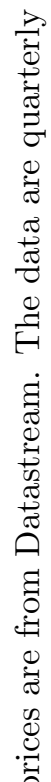
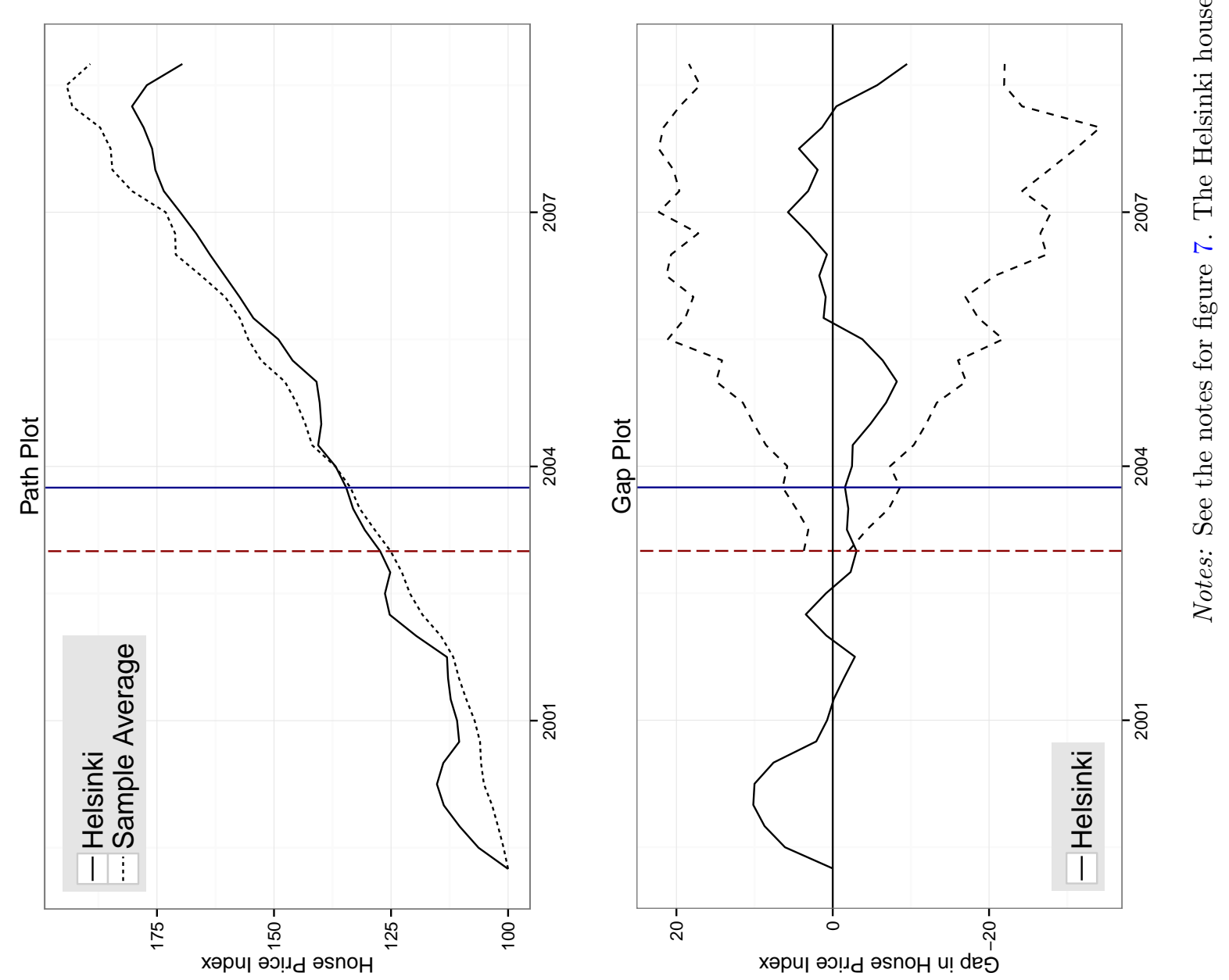


\section{F Appendix: Synthetic Control Gap Estimates (For Online Publica-}

tion)

Table 10: Synthetic Control-Estimated Effects of IO Loans

\begin{tabular}{|c|c|c|c|c|c|}
\hline \multirow[b]{2}{*}{ Treated Unit } & \multirow[b]{2}{*}{ RMSFE } & \multicolumn{2}{|c|}{ Gap } & \multicolumn{2}{|c|}{ Gap/Path } \\
\hline & & Boom & Bust & Boom & Bust \\
\hline \multicolumn{6}{|c|}{ Panel 1: Coastal Cities; Unadjusted Macro Data } \\
\hline CopenhagenCity & 42.14 & $52.32^{*}$ & $-30.20^{*}$ & 0.77 & 2.98 \\
\hline CopenhagenSurroundings & 7.52 & $40.32^{*}$ & $-32.09^{*}$ & 0.72 & 2.54 \\
\hline EasternJutland & 2.96 & 8.48 & $-14.61^{*}$ & 0.20 & -43.11 \\
\hline EasternZealand & 5.21 & $35.98^{*}$ & $-31.18^{*}$ & 0.70 & 2.37 \\
\hline Fyn & 2.37 & -3.04 & $-14.71^{*}$ & -0.08 & -10.54 \\
\hline NorthernJutland & 3.19 & -1.82 & $-5.89^{*}$ & -0.07 & -0.57 \\
\hline NorthernZealand & 9.67 & $36.58^{*}$ & $-38.42^{*}$ & 0.70 & 2.05 \\
\hline SouthernJutland & 3.09 & -5.44 & $-6.63^{*}$ & -0.19 & -0.67 \\
\hline WesternJutland & 4.67 & -9.37 & -0.65 & -0.36 & -0.04 \\
\hline WestSouthZealand & 7.33 & $19.94^{*}$ & $-26.03^{*}$ & 0.56 & 3.87 \\
\hline \multicolumn{6}{|c|}{ Panel 2(a): All Cities; Standardized Macro Data } \\
\hline Copenhas & 42.14 & $52.32^{*}$ & $-30.20^{*}$ & 0.77 & 2.97 \\
\hline CopenhagenSurroundings & 7.53 & 40.29 & $-32.06^{*}$ & 0.72 & 2.54 \\
\hline EasternJutland & 2.06 & 5.65 & $-36.14^{*}$ & 0.13 & -106.69 \\
\hline EasternZealand & 5.94 & 34.05 & $-31.36^{*}$ & 0.66 & 2.38 \\
\hline Fyn & 1.58 & -4.11 & $-31.18^{*}$ & -0.11 & -22.33 \\
\hline NorthernJutland & 2.64 & -3.61 & $-19.94^{*}$ & -0.14 & -1.92 \\
\hline NorthernZealand & 9.78 & 36.52 & $-38.75^{*}$ & 0.70 & 2.07 \\
\hline SouthernJutland & 2.12 & -6.81 & $-25.34^{*}$ & -0.24 & -2.55 \\
\hline WesternJutland & 3.60 & -10.61 & $-20.54^{*}$ & -0.41 & -1.29 \\
\hline WestSouthZealand & 7.34 & 19.94 & $-25.99 *$ & 0.56 & 3.87 \\
\hline \multicolumn{6}{|c|}{ Panel 2(b): All Cities; Unadjusted Macro Data } \\
\hline CopenhagenCity & 42.14 & $52.32^{*}$ & $-30.20^{*}$ & 0.77 & 2.98 \\
\hline CopenhagenSurroundings & 7.52 & $40.32^{*}$ & $-32.09^{*}$ & 0.72 & 2.54 \\
\hline EasternJutland & 2.06 & 5.63 & $-36.21^{*}$ & 0.13 & -106.88 \\
\hline EasternZealand & 5.21 & 35.97 & $-31.23^{*}$ & 0.70 & 2.37 \\
\hline Fyn & 1.60 & -4.51 & $-30.81^{*}$ & -0.12 & -22.06 \\
\hline NorthernJutland & 2.61 & -3.31 & $-19.68^{*}$ & -0.13 & -1.89 \\
\hline NorthernZealand & 9.77 & 36.52 & $-38.74^{*}$ & 0.70 & 2.07 \\
\hline SouthernJutland & 2.16 & -7.55 & $-25.22^{*}$ & -0.26 & -2.54 \\
\hline WesternJutland & 3.62 & -11.01 & $-20.86^{*}$ & -0.42 & -1.31 \\
\hline WestSouthZealand & 7.33 & 19.94 & $-26.03^{*}$ & 0.56 & 3.87 \\
\hline
\end{tabular}

Notes: See the notes for table 5. 
Table 10 Continued

\begin{tabular}{|c|c|c|c|c|c|}
\hline \multirow[b]{2}{*}{ Treated Unit } & \multirow[b]{2}{*}{ RMSFE } & \multicolumn{2}{|c|}{ Gap } & \multicolumn{2}{|c|}{ Gap/Path } \\
\hline & & Boom & Bust & Boom & Bust \\
\hline \multicolumn{6}{|c|}{ Panel 3(a): Quarterly HPIs; Coastal Cities; Standardized Macro Data } \\
\hline CopenhagenCity & 16.57 & $68.73^{*}$ & $-28.55^{*}$ & 0.82 & 1.40 \\
\hline CopenhagenSurroundings & 2.36 & $69.10^{*}$ & $-26.26^{*}$ & 0.82 & 1.43 \\
\hline EasternJutland & 1.47 & $43.73^{*}$ & $-17.71^{*}$ & 0.70 & 1.54 \\
\hline EasternZealand & 3.77 & $58.29^{*}$ & $-33.93^{*}$ & 0.79 & 1.29 \\
\hline Fyn & 0.81 & $40.89^{*}$ & -11.61 & 0.74 & 1.51 \\
\hline NorthernJutland & 1.69 & $19.25^{*}$ & -10.13 & 0.53 & 2.31 \\
\hline NorthernZealand & 3.20 & $63.94^{*}$ & $-36.93^{*}$ & 0.81 & 1.28 \\
\hline SouthernJutland & 0.76 & $23.70^{*}$ & -10.42 & 0.62 & 1.74 \\
\hline WesternJutland & 3.54 & $34.36^{*}$ & $-27.16^{*}$ & 0.69 & 1.41 \\
\hline WestSouthZealand & 0.77 & $21.28^{*}$ & -18.26 & 0.63 & 21.65 \\
\hline \multicolumn{6}{|c|}{ Panel 3(b): Quarterly HPIs; Coastal Cities; Unadjusted Macro Data } \\
\hline CopenhagenCity & 16.57 & $68.73^{*}$ & $-28.55^{*}$ & 0.82 & 1.40 \\
\hline CopenhagenSurroundings & 2.36 & $69.10^{*}$ & $-26.25^{*}$ & 0.82 & 1.43 \\
\hline EasternJutland & 1.47 & $43.73^{*}$ & $-17.72 *$ & 0.70 & 1.54 \\
\hline EasternZealand & 3.77 & $58.29^{*}$ & $-33.93^{*}$ & 0.79 & 1.29 \\
\hline Fyn & 0.93 & $42.65^{*}$ & -11.84 & 0.77 & 1.54 \\
\hline NorthernJutland & 1.72 & $21.25^{*}$ & -9.63 & 0.59 & 2.20 \\
\hline NorthernZealand & 3.20 & $63.94^{*}$ & $-36.93^{*}$ & 0.81 & 1.28 \\
\hline SouthernJutland & 0.80 & $23.61^{*}$ & -10.24 & 0.62 & 1.71 \\
\hline WesternJutland & 3.56 & $34.39^{*}$ & $-27.15^{*}$ & 0.69 & 1.41 \\
\hline WestSouthZealand & 0.49 & $28.34^{*}$ & -3.02 & 0.84 & 3.58 \\
\hline \multicolumn{6}{|c|}{ Panel 3(c): Quarterly HPIs; All Cities; Standardized Macro Data } \\
\hline CopenhagenCity & 16.57 & $68.73^{*}$ & $-28.55^{*}$ & 0.82 & 1.40 \\
\hline CopenhagenSurroundings & 2.31 & $69.03^{*}$ & $-26.24^{*}$ & 0.82 & 1.43 \\
\hline EasternJutland & 1.47 & 43.71 & $-17.74^{*}$ & 0.70 & 1.54 \\
\hline EasternZealand & 3.77 & $58.28^{*}$ & $-33.92 *$ & 0.79 & 1.29 \\
\hline Fyn & 0.81 & 40.43 & -12.85 & 0.73 & 1.67 \\
\hline NorthernJutland & 5.48 & 10.92 & $-56.43^{*}$ & 0.30 & 12.87 \\
\hline NorthernZealand & 3.20 & $63.94^{*}$ & $-36.94^{*}$ & 0.81 & 1.28 \\
\hline SouthernJutland & 0.72 & 20.03 & $-19.79 *$ & 0.53 & 3.31 \\
\hline WesternJutland & 3.51 & 34.38 & $-27.15^{*}$ & 0.69 & 1.41 \\
\hline WestSouthZealand & 0.35 & 7.15 & $-39.17^{*}$ & 0.21 & 46.43 \\
\hline \multicolumn{6}{|c|}{ Panel 3(d): Quarterly HPIs; All Cities; Unadjusted Macro Data } \\
\hline CopenhagenCity & 16.57 & $68.73^{*}$ & $-28.55^{*}$ & 0.82 & 1.40 \\
\hline CopenhagenSurroundings & 2.30 & $69.02^{*}$ & $-26.22^{*}$ & 0.82 & 1.43 \\
\hline EasternJutland & 1.47 & 43.71 & $-17.72^{*}$ & 0.70 & 1.54 \\
\hline EasternZealand & 3.77 & $58.27^{*}$ & $-33.92^{*}$ & 0.79 & 1.29 \\
\hline Fyn & 0.83 & 40.84 & -11.96 & 0.74 & 1.55 \\
\hline NorthernJutland & 1.74 & 21.61 & -9.38 & 0.60 & 2.14 \\
\hline NorthernZealand & 3.20 & $63.94^{*}$ & $-36.94^{*}$ & 0.81 & 1.28 \\
\hline SouthernJutland & 0.72 & 20.12 & $-19.62^{*}$ & 0.53 & 3.28 \\
\hline WesternJutland & 3.50 & 34.34 & $-27.13^{*}$ & 0.69 & 1.41 \\
\hline WestSouthZealand & 0.35 & 7.13 & $-39.24^{*}$ & 0.21 & 46.52 \\
\hline
\end{tabular}

